Autobiographical odor memory

Johan Willander

Doctoral Thesis in Psychology at Stockholm University, Sweden 2007 



\title{
Autobiographical Odor Memory
}

\author{
Johan Willander
}

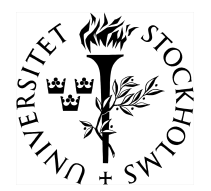

Stockholm University 
@ Johan Willander, Stockholm 2007

Cover image @iStockphoto.com/Sverdelov

\section{ISBN (978-91-7155-494-9)}

Printed in Sweden by US-AB, Stockholm 2007

Distributor: The Department of Psychology, Stockholm University 
To my wonderful family 



\section{Abstract}

In the present thesis, three empirical studies investigate autobiographical odor memory with regard to: (a) whole life-span age distributions, (b) phenomenological experience, (c) semantic processing, and (d) odor imagery. Study I explored potential influences of cue type (words, pictures, odors) on the retrieval of autobiographical memories. The results indicated that odorevoked events were older than memories evoked by words and pictures. The bump for olfactory evoked information peaked in the first decade of life $(<10$ years of age), whereas the bump of the word- and picture-evoked age distributions peaked in the second decade (i.e., 11-20 years of age). Also, olfactory evoked events were associated with stronger feelings of being brought back in time. Study II investigated the influence of verbal processing on the retrieval of autobiographical olfactory information. The results revealed that semantic knowledge (i.e., the odor name) affected both the age distribution and phenomenological experience. Also, olfactory memories were associated with a higher emotional arousal. Study III addressed the influences of olfactory imagery on the age distribution and phenomenological experiences. The results showed that events evoked by odor imagery were older than memories evoked by words. No differences in phenomenological experiences were found between the two cue conditions. Based on these findings, it is suggested that (a) memories evoked by olfactory information are older than memories evoked by verbal and visual information, (b) odor memories are more emotional and associated with stronger feelings of being brought back in time, (c) knowledge of an odor's name produces a shift from a more perceptually to a more conceptually driven retrieval, and that (d) imagined odor cues mimic the age distribution of events evoked by real odors. Overall, the results suggest that memories triggered by the olfactory sensory system are different from memories evoked by verbal or visual information.

Keywords: Autobiographical odor memory, autobiographical memory, olfaction, olfactory imagery, episodic memory, age distribution, phenomenological experience, emotion 



\section{Acknowledgement}

Life is great when you are surrounded by wonderful people! Words are not enough to express how much I appreciate and how thankful I am to the following:

Maria Larsson, my supervisor and dear friend, who skillfully guided me through the universe of memory and olfaction. Many thanks for sharing your knowledge, insightful advices, support, and generosity!

All of my friends and colleagues at the Department of Psychology, Stockholm University, for all the nice talks and friendship. I would also like to send a special thanks to (in no particular order) Stephan Baraldi, Åke Wahlin, Stefan Wiens, Åke Hellström, Margareta Hedner, Jonas Olofsson, Lars-Göran Nilsson, Farah Moniri, Victoria Blom, Göran Söderlund, Gustaf Törngren, Anna-Lena Erixson, Henry Montgonery, Heidi Selenius, Jenny Laurell, Marie Gustafsson, Nathalie Peira, Armita Golkar, Lars Bergman, Ann-Charlotte Smedler, Sverker Sikström, Neda Kemiri, Ola Sternäng, Mats Olsson, Johan Lundström, Fredrik Jönsson, Steven Nordin, Daniel Broman, for the friendship, encouragement, and inspiration.

No words to convey my love and gratefulness to my awesome wife and best friend Erika and our wonderful little son Julius. Thanks for everything!

My wonderful parents, Kerstin and Magnus, who gave me a nose to smell with and a bunch of neurons to play with. Josefine and Johanna - what is a brother without his sisters? Thank you for all love and support! My grandmother Inez for all love and great fun! The Anderson family - Doris, Owe, Ida, and Emil - you rock! Many thanks to Bunten - what a normal place the world would have been without you. There are so many people I would like to thank. I'm sorry I can't fit you all into this page, but you're always in my mind.

Heartily thanks to Timo Mäntylä from the Department of Psychology, Umeå, and Stefan Wiens from the Department of Psychology, Stockholm University, for taking the time to review and comment the present thesis. 
It takes two to tango: ideas and financial support. Great thanks to the following for funding the Autobiographical Memory Projects, journeys, and conferences: Swedish Research Council (421-2001-3838 to Maria Larsson), Lars Hierta Minnesfond, Knut och Alice Wallenbergs stiftelse, and The Department of Psychology, Stockholm University.

Finally, to all of the fantastic participants in the three Autobiographical Memory Projects. You made it possible: Thank you so much! 




\section{List of studies}

The present doctorial thesis is based on the following studies:

I. Willander, J., \& Larsson, M. (2006). Smell your way back to childhood: Autobiographical odor memory. Psychonomic Bulletin \& Review, 13(2), 240-244.

II. Willander, J., \& Larsson, M. (2007). Olfaction and emotion: The case of autobiographical memory. Memory \& Cognition, 35(7), 1659-1663.

III. Willander, J., \& Larsson, M. (submitted). The mind's nose and autobiographical odor memory.

Paper I and II are printed with permission from The Psychonomic Society. 



\section{Contents}

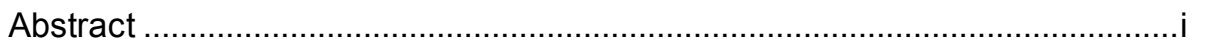

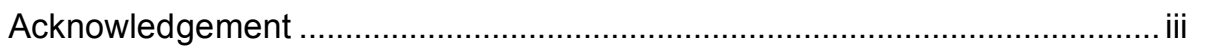

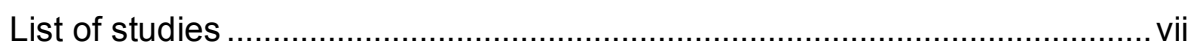

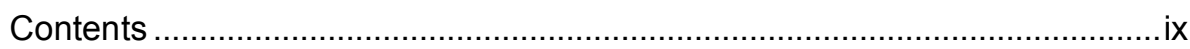

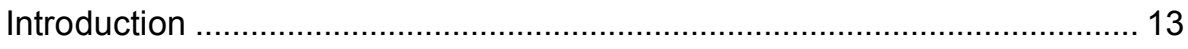

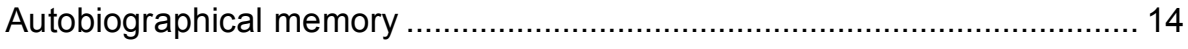

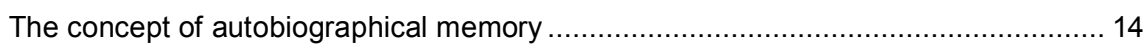

Models of autobiographical memory ................................................................ 15

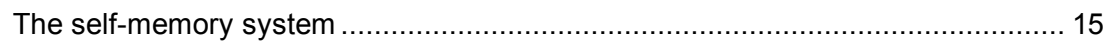

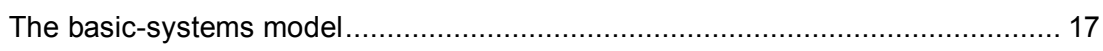

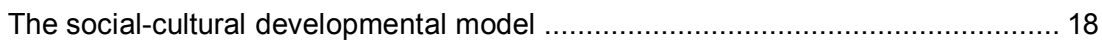

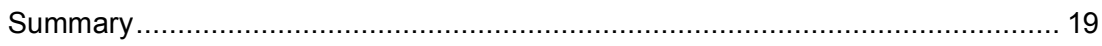

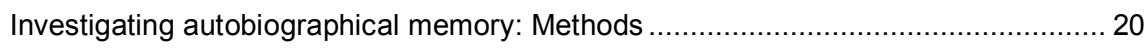

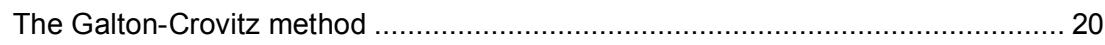

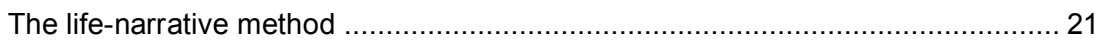

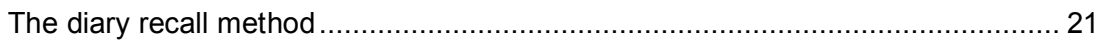

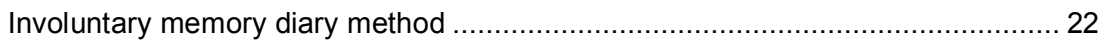

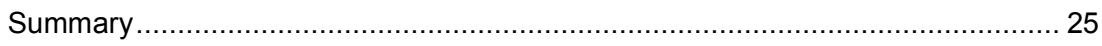

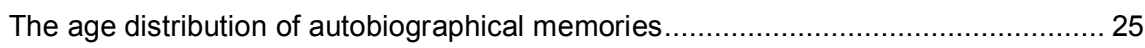

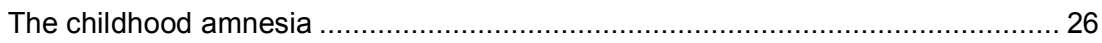

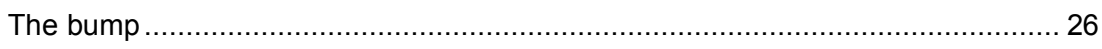

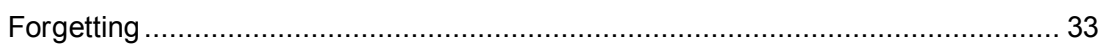

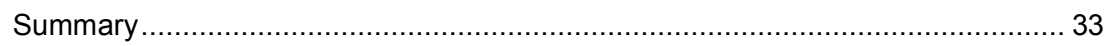

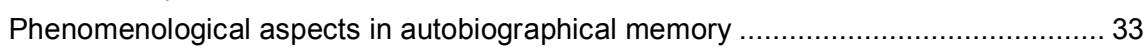

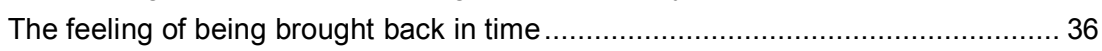

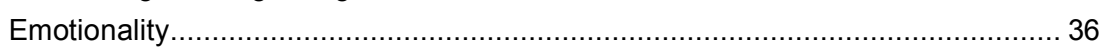

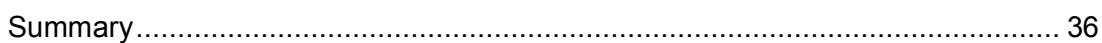

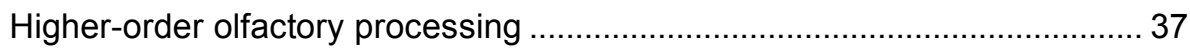

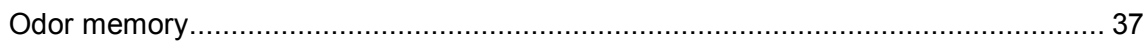

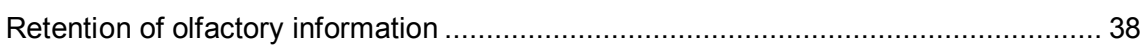

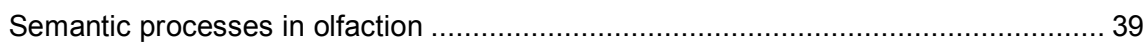




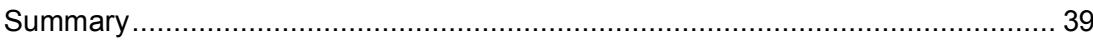

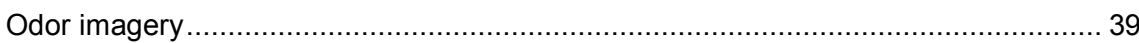

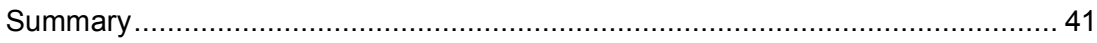

Autobiographical odor memory ........................................................ 42

The age distribution of autobiographical odor memories....................................... 42

Phenomenological experience in odor-evoked memories ....................................... 43

The efficiency of odors as cues to autobiographical memories ............................... 44

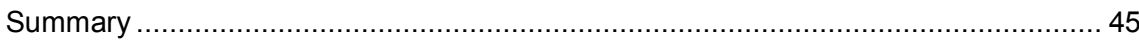

Overview of empirical studies .......................................................... 46

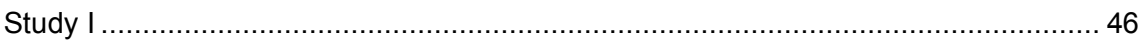

Aim

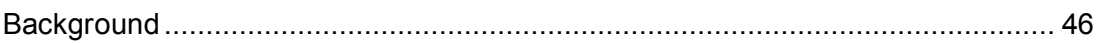

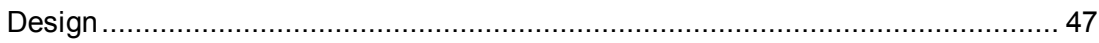

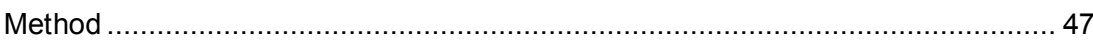

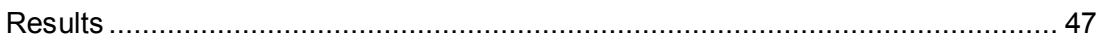

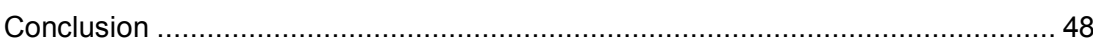

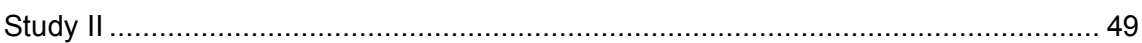

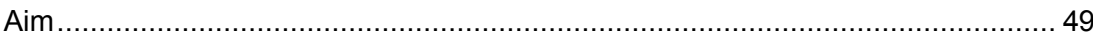

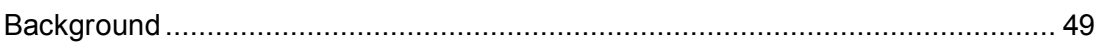

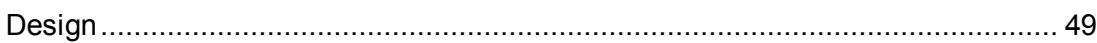

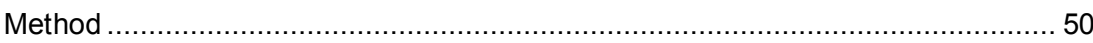

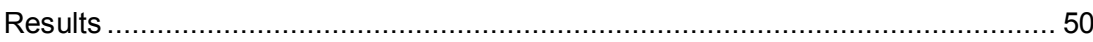

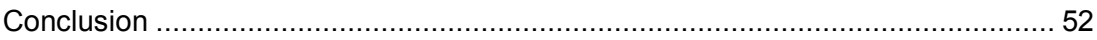

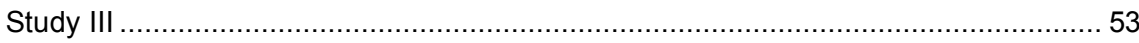

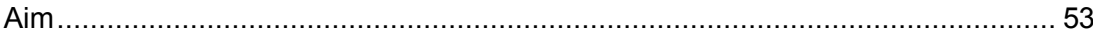

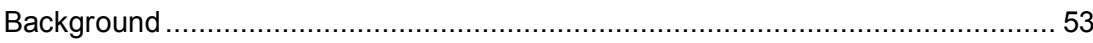

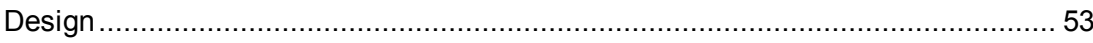

Method

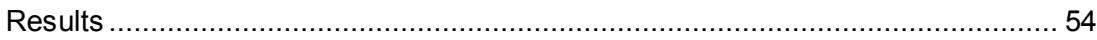

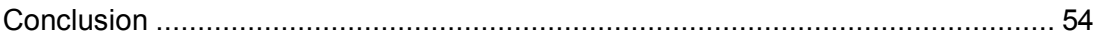

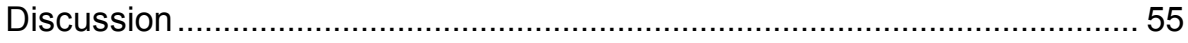

The age distribution of autobiographical odor memory ......................................... 55

Perceptual and conceptual processing .................................................... 56

Retrieval modes and selection strategies ................................................... 57

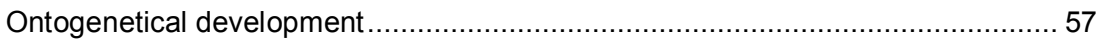

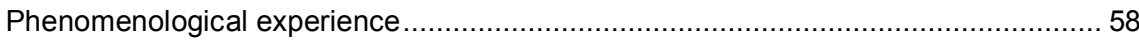

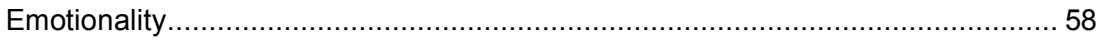

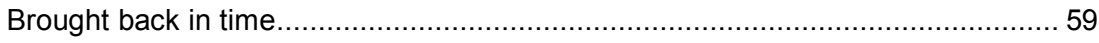

Olfactory imagery and phenomenological experiences .................................... 59

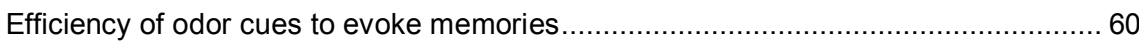

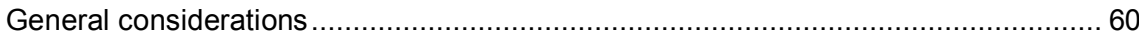

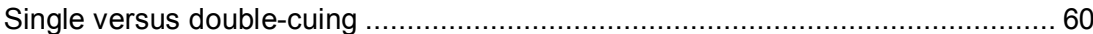


Veridicality of retrieved events......

60

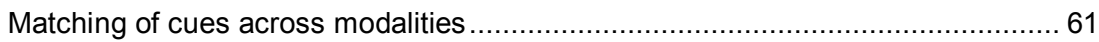

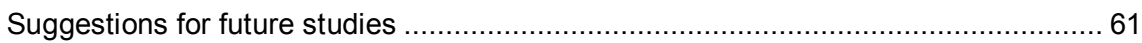

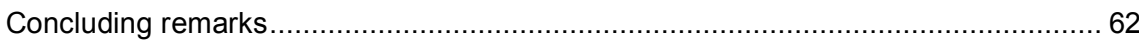

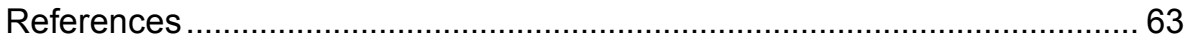






\section{Introduction}

The olfactory system is the phylogenetically and ontogenetically oldest sensory system. The sense of smell is important to human beings and is in constant use because environmental odors must be monitored on a continuous basis. Although the olfactory system has been regarded as less important than our primary senses, vision and hearing, it plays a central role in the everyday life of humans. Even if the sense of smell may have evolved as a system for evaluating whether a particular food is edible, or act as a warning system for potential threats (e.g., a fire), it also serves important social functions, mediates well-being, and has the potential to influence mood and to evoke memories.

In Du coté de chez Swann, Proust (1919) described the recollection of a vivid and emotional childhood event that was evoked by the taste/smell of a Madeleine cookie. Based on this description the proustian phenomenon has been used to denote the hypothesis that odors evoke older, more emotional, and vivid memories than information evoked by other cue types. Until recently, support for the proustian phenomenon has mostly relied on anecdotal sources. Scientific evidence is yet scarce regarding the nature of autobiographical odor memory. Although research has focused on memory for odors, most of these efforts concern episodic memory for a set of odors over time (e.g., odor recognition) rather than the potential of an odor to evoke a specific autobiographical event.

The present thesis is devoted to the exploration of autobiographical odor memory and how information evoked by the olfactory sense may differ from memories evoked by visual and verbal information. Three separate empirical studies investigated autobiographical odor memory with regard to: (a) whole life-span age distributions, (b) phenomenological experience, (c) conceptual/semantic processing, and (d) olfactory imagery. 


\section{Autobiographical memory}

Memory is not a single process or system, but a neurocognitive capacity consisting of several systems and processes enabling encoding, storage and retrieval of information (Tulving, 2000). One of the most influential hypothesized organizations of human memory is the multiple memory systems view. According to this view, memory comprises five different systems: procedural memory, perceptual representation system (PRS), semantic memory, working memory, and episodic memory (Schacter \& Tulving, 1994). Procedural memory processes information related to procedural and motor skills (Gupta \& Cohen, 2002). The perceptual representation system (PRS), or priming, is a form of memory that is manifested by improved performance on a task in the absence of consciousness recollection of a preceding experience (Graf \& Schacter, 1985; Roediger, 1990). Semantic memory retains factual knowledge about the world (e.g., What is the capital of France?) (Prince, Tsukiura, \& Cabeza, 2007; Tulving, 1983). Working memory is a temporary store of information that is of immediate use (Baddeley, $2000,2003)$. Here, the amount of information that can be held at a given moment is highly limited both with regard to amount and temporal duration (Baddeley, 1994, 2003; Schacter \& Tulving, 1994). Episodic memory handles personally experienced events (Tulving, 1983, 2002). A defining aspect of episodic memory (i.e., autobiographical memory) is mental time travel, "episodic memory does exactly what the other forms of memory do not and cannot do - it enables the individual to mentally travel back into her personal past" (Tulving, 1998, p. 266).

\section{The concept of autobiographical memory}

Autobiographical memory concerns personal events from one's life. However, different terms have been used interchangeably to describe autobiographical memory, such as episodic memory, event memory, or everyday memory. Thus, the nomenclature and distinctiveness of autobiographical memory is under debate (Banaji \& Crowder, 1989; Bruce, 1991; Ceci \& Bronfenbrenner, 1991; Conway, 1991; Loftus, 1991).

Broadly, four different views on the relationship between autobiographical memory and other forms of memory have been articulated: (1) Autobio- 
graphical memory is equivalent to episodic memory (e.g., Gilboa, 2004). According to Tulving, "autobiographical memory is just another name for episodic memory". This notion is supported by fMRI studies, indicating that autobiographical memories activate similar brain areas as do other episodic memory tasks (e.g., Gilboa, 2004). In this vein, Bower (2000, p. 23) argued that "autobiographical memories are typically dated episodic memories, although people also may have abstract generalizations about long stretches of their life that are not themselves distinct episodes". (2) Autobiographical memory is a subdomain of episodic memory, representing naturalistic episodic memories (e.g., Conway, 1991). (3) Autobiographical memory is an integration between episodic and semantic memory (Cabeza \& St Jacques, 2007). (4) Autobiographical memory is the result of interactions among several systems/functions, such as episodic memory, semantic memory, narrative, imagery, language, and social functions (Fivush \& Nelson, 2004; Nelson \& Fivush, 2004; Rubin, 2005a, 2006).

\section{Models of autobiographical memory}

The construction of events is complex and an integration of data from various domains (e.g., neurobiology, perception, imagery, and language) is required to understand the operations of autobiographical memory. In the following section, three influential models of autobiographical memory will be presented. The models are: (1) the self-memory system (Conway \& PleydellPearce, 2000), (2) the basic-systems model (Rubin, 2005a, 2006), and (3) the social-cultural developmental model (Nelson \& Fivush, 2004).

\section{The self-memory system}

The self-memory system model defines autobiographical memories as transitory mental constructions generated from information of the autobiographical knowledge base (Conway \& Pleydell-Pearce, 2000). Two aspects of the model are of special interest and will be covered: the knowledge base and the retrieval processes.

\section{The autobiographical knowledge base}

Autobiographical memories comprise information that varies with regard to degree of specificity (Anderson \& Conway, 1993). In the autobiographical knowledge base, information may be arranged following three levels of specificity: lifetime periods, general events, and event-specific knowledge (ESK). A graphical illustration of the autobiographical knowledge base is presented in Figure 1. To retrieve a full-blown autobiographical memory, information from all three levels needs to be represented in the recollection (Conway \& Pleydell-Pearce, 2000). For example, a memory of tasting port wine for the first time at restaurant $\mathrm{E}$ while living in town $\mathrm{A}$, carries infor- 
mation from all three specificity levels. In this example, "living in town A" represents lifetime periods and "eating at restaurant E" represents the level of general events. An example of event-specific knowledge of the target event is the chemosensory recollection of the tasted port wine.

Lifetime periods concern our general knowledge about longer periods in life, such as "when I lived in town B". Although lifetime periods can be highly distinctive it is also worth noting that potential beginnings and ends also may be vague. Evidently, many lifetime periods may run in parallel, (e.g., living in town B and playing in orchestra C). At a more specific level, general events represent thematically related events that occur repeatedly, such as playing pool every Thursday. The most specific level of the autobiographical knowledge base is the event-specific knowledge. Event-specific knowledge may be defined as information represented in episodic memory and thus concerns unique event features related to the core themes of episodic memory: what, where, and when?

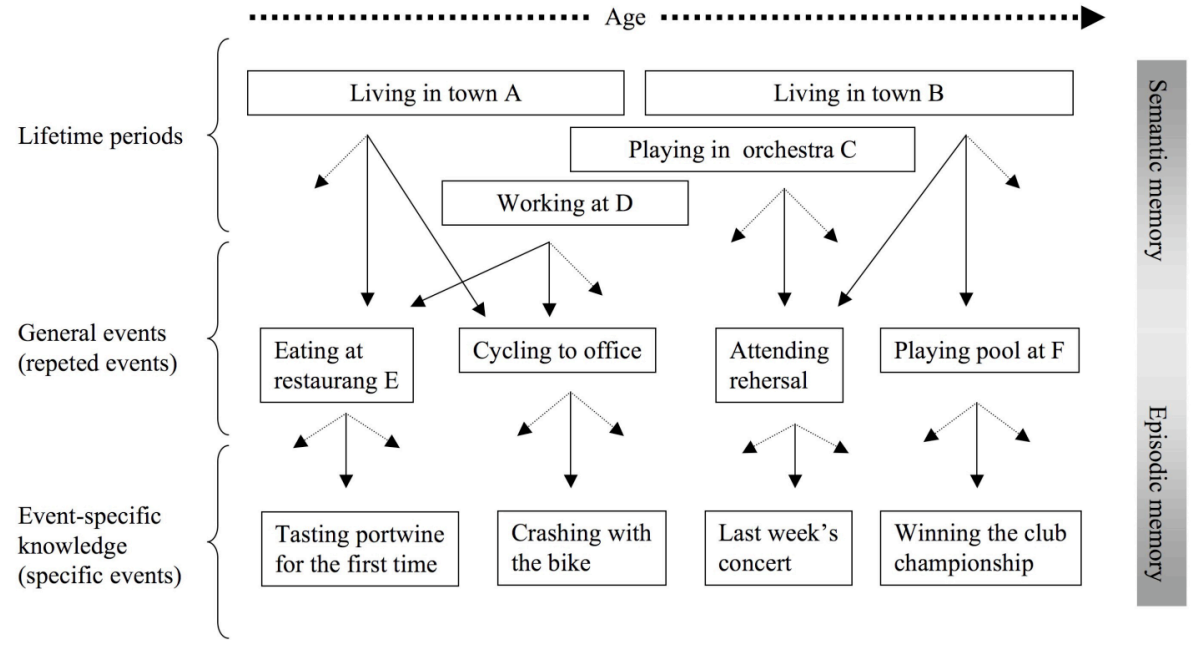

Figure 1. The structure of the self memory system (adapted from Cabeza \& St Jacques, 2007; Conway \& Pleydell-Pearce, 2000).

\section{Retrieval of autobiographical information}

Two retrieval processes of autobiographical memories have been postulated: generative (strategic) and automatic (direct) (Conway \& Pleydell-Pearce, 2000; Norman \& Bobrow, 1979). In generative retrieval, the search for events is executed in a strategic and cyclic form, such that retrieval cues are compared to stored information. If a cue matches a representation, the event is recalled. However, if a cue does not match the stored information the search process continues. In contrast, direct retrieval denotes an automatic form of retrieval from autobiographical memory. Here, the strategic and 
cyclic search process is bypassed and the cues map directly onto congruent event information that results in a spread of activation in the autobiographical knowledge base. Typically this type of activation produces an effortless and immediate recollection (Conway \& Pleydell-Pearce, 2000). Highly perceptual cues such as odors have been suggested to elicit a direct and automatic retrieval process, whereas generative retrieval has been associated with verbal cues (Conway \& Pleydell-Pearce, 2000).

\section{The basic-systems model}

The core of the basic systems model (BSM) is that autobiographical memory is constructed from a number of independent basic systems (Rubin, 2005a, 2006). Each system is conceived of as a separate network, with its own behavioral properties, storage, and neural substrates, and these networks interact to produce autobiographical memory information (Rubin, 2006).

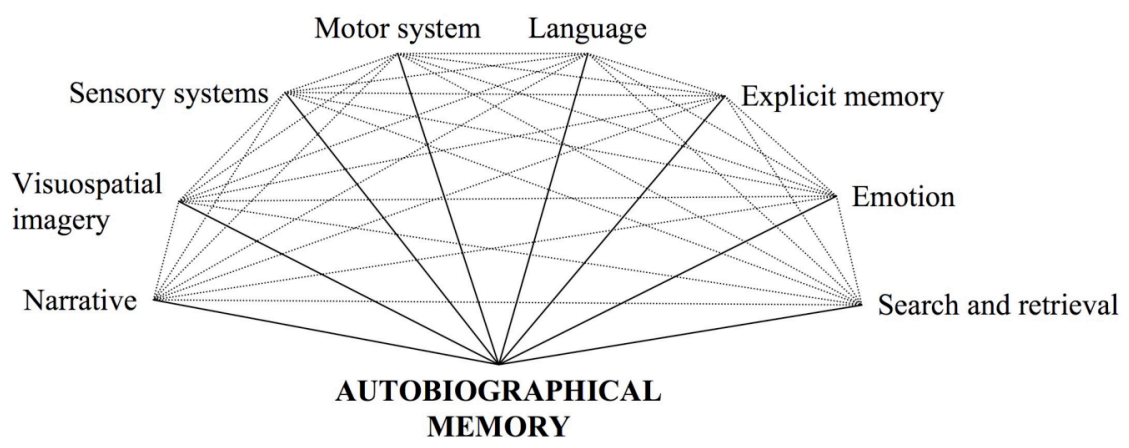

Figure 2. A graphical illustration of the basic-systems model. Potential interactions among the basic systems are represented by the dotted lines.

According to the BSM, each system has a specific role in the recollection of events. The postulated basic systems are: sensory systems, spatial imagery, emotion, language, narrative, motor activity, explicit memory, search and retrieval (Rubin, 2006). An illustration of the model is provided in Figure 2. For example, vision provides visual information to the brain that serves as a prerequisite for our ability to produce visual images of previous events. However, imagery can take many forms and objects may also be represented in a non-visual format such as spatial imagery. The olfactory system registers and processes information in a chemosensory format. Like the visual sense is involved in visual imagery, the olfactory system enables reproduction of olfactory representations in the absence of relevant stimuli (Djordjevic, Zatorre, Petrides, \& Jones-Gotman, 2004; Stevenson \& Case, 2005). Thus, the olfactory sensory system constitute a prerequisite for the ability to integrate chemosensory information in autobiographical memories 
(Herz, 2004). Naturally, the formation and recollection of events also include aspects other than perceptual representations. One such example is emotions, which are a set of processes that modulate the experience of an event (Berntsen \& Rubin, 2006; Phelps, 2004). In the study of autobiographical memory, emotional aspects such as pleasantness and intensity are often highlighted and focused upon (Berntsen \& Rubin, 2002; Herz \& Schooler, 2002). In addition to perceptual and emotional processing, language also plays a fundamental role for autobiographical memory, because events may be recoded and stored in a linguistic format (Rubin, 2006; Schooler \& EngstlerSchooler, 1990). Related to language is the narrative system that provides individuals with a life story by binding together events on a thematic or causal basis (Barclay, 1999; Robinson \& Taylor, 1998). Further, another important basic system handles motor information. Evidence indicates that motor activity (i.e., procedural memory) interact with episodic memory, such that procedural activities influence encoding and retrieval of episodic information (Kormi-Nouri, 2000; Kormi-Nouri, Nyberg, \& Nilsson, 1994; Nyberg \& Nilsson, 1995; Nyberg et al., 2001). Thus, for a given event, each of the systems process system-relevant information and provide a unique analysis contributing to the formation of autobiographical memory. The recollection of an autobiographical event is initiated by search and retrieval processes. These processes enable selection and maintenance of relevant information needed for the recollection of events (Rubin, 2006).

\section{The social-cultural developmental model}

The social-cultural developmental model highlights the interaction among various functions, such as memory, language, and self-representations in the production of autobiographical memories (Nelson \& Fivush, 2004). More specifically, the gradual development of cognitive functions (e.g., episodic and semantic memory) and social functions (e.g., language communication) result in the emergence of a functional autobiographical memory system at approximately the age of five years (Fivush \& Nelson, 2004; Nelson \& Fivush, 2004). An illustration of the social-cultural developmental model is provided in Figure 3. According to the model, the development of autobiographical memory continues into adolescence (Nelson \& Fivush, 2004). It is worth noting that events may be recalled prior to the age of five, but it is highly likely that these early memory representations only are fragmental in nature (Bruce et al., 2005; Nelson \& Fivush, 2004).

A central aspect of the social-cultural developmental model is the role of language in the development of autobiographical memory (Fivush, Haden, \& Adam, 1995; Fivush \& Nelson, 2004; Nelson \& Fivush, 2004). Specifically, Nelson and Fivush (2004) suggested three accounts of language in the development of autobiographical memory: (a) autobiographical memories are communicated in verbal format, (b) communication with others influence the 
representation of memories such that they become more organized, and that language (c) facilitates awareness of memories as representations of the past.

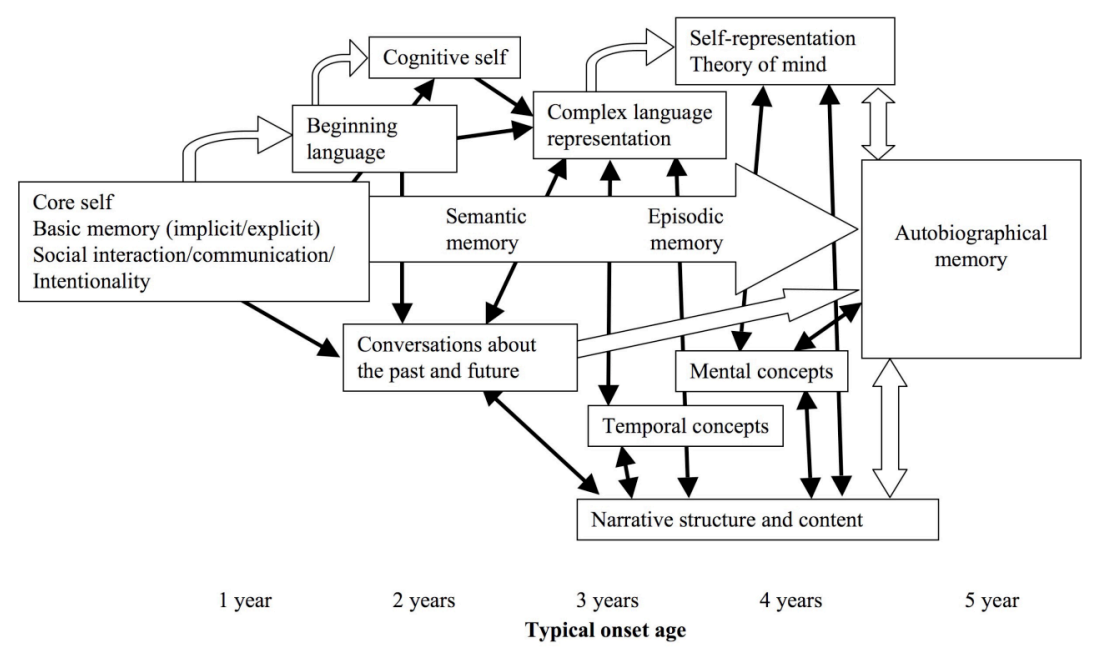

Figure 3. The social-cultural developmental model of autobiographical memory (adapted from Nelson \& Fivush, 2004).

\section{Summary}

Three different models of autobiographical memory were presented: the selfmemory system, the basic-systems model, and the social-cultural developmental model. In the self-memory systems model, events are temporary constructions built up from information of the autobiographical knowledge base. The basic-systems model argues that personal events are the result of several interacting basic systems. Finally, the social-cultural developmental model emphasizes the role played by language and social interaction in the formation of autobiographical memories. 


\section{Investigating autobiographical memory: Methods}

Autobiographical memories may be assessed differently depending on the specific research question (e.g., Berntsen \& Rubin, 2004, 2006; Crovitz \& Schiffman, 1974; Fromholt et al., 2003; Herz \& Schooler, 2002; Larsen, Schrauf, Fromholt, \& Rubin, 2002; Thomsen \& Berntsen, 2005). The methods presented in the following section are well established and have produced reliable findings in the study of autobiographical memory. A summary of the reviewed methods can be found in Table 1 .

\section{The Galton-Crovitz method}

One of the most utilized methods for studying autobiographical memory is the Galton-Crovitz method (Rubin, 2005b). This method is also known as the word-cue method (Crovitz \& Schiffman, 1974; Rubin, 2005b). The procedure of the Galton-Crovitz method is as follows: participants are given a number of cues (e.g., words, pictures, odors) and asked to produce an autobiographical memory for each cue. In instances of successful retrieval, the participants are instructed to provide a short description of the event and also to rate it on various experiential dimensions (e.g., pleasantness, vividness, the feeling of being brought back in time). When all memories have been retrieved, participants are asked to go back to each memory description and date it. The dating of events is typically performed after the retrieval phase because dating often requires accessing more memories related to it. Thus, the dating process may lead participants to be more oriented towards specific periods of life that may affect the retrieval processes (Rubin, 2005b). Three different procedures for dating memories are used: the participants' age at event (e.g., Chu \& Downes, 2000), the date on which the event occurred (e.g., Rubin \& Schulkind, 1997b), and the time passed since the event occurred (e.g., Rubin, 1982).

The Galton-Crovitz method has proved to be a reliable method and has produced replicable results with regard to the age distribution of word-cued events (e.g., Janssen, Chessa, \& Murre, 2005; Rubin, Rahhal, \& Poon, 1998; Rubin \& Schulkind, 1997a, 1997b). This method has several advantages. For example, any type of cue can be used with the Galton-Crovitz method, such as words, pictures, or odors (e.g., Rubin, Groth, \& Goldsmith, 1984). Also, the method is powerful in that retrieved events may be compared across various cue types with regard to age distributions, phenomenological experience, and retrieval latencies (Rubin, 2005b). A disadvantage of the method is that the veridicality of the retrieved events is difficult to evaluate. One way to verify the accuracy of the retrieved memories is to consult relatives of the participants. However, this validation procedure is extremely time consuming and may not even increase reliability. 
A special case of the Galton-Crovitz method is the double-cuing method (Chu \& Downes, 2002; Herz \& Schooler, 2002). Here, participants are presented with cues and asked to relate any memory for a given cue. When all cues have been presented, participants are re-exposed to the event descriptions and provided with a new set of cues. The rationale for providing additional cues is to probe for more information concerning the event. The extra cues provided may vary in different sensory formats, such as words or odors. The double-cuing method enables comparisons of retrieved event information across cue types controlling for selection of events related to the specific cue (Chu \& Downes, 2002; Herz \& Schooler, 2002). However, a potential disadvantage with the double-cuing procedure is the complexity of the procedure that may reduce reliability and validity of the data (cf. Study II of the present thesis).

\section{The life-narrative method}

In the life-narrative method, participants are simply asked to provide their life story in an interview format. Here, events are not cued but participants are instructed to engage in free association. Because participants provide their life in narrative form, events are related in a continuous stream of autobiographical information. As a consequence, events are not distinctly separated as in the Galton-Crovitz method. Therefore the life-narrative method requires that unique events are identified in the life story to enable analysis. The life-narrative method allows memories to be analyzed with regard to phenomenological experiences and age distributions. In a study by Fromholt et al. (2003) differences in autobiographical memory between old and very old adults and clinical condition (healthy, depressed, demented) were investigated. Participants were instructed to either talk about important events from their lives or to provide events for a set of word cues. Importantly, the results indicated that both retrieval conditions (life-narrative and word-cue) produced similar age distributions of memories. A major advantage of the life-narrative method is that events can be studied in the context of peoples' lives and that detailed event descriptions may be extracted. However, a disadvantage is that the life-narrative method may produce large data quantities resulting in time consuming analyses. Also, the data may be limited in content because participants typically try to maintain coherence in their respective life-story (Rubin, 2005b).

\section{The diary recall method}

A problem associated with experimental methods of autobiographical memory retrieval is that veridicality cannot be assessed. However, this problem is addressed and resolved by the diary recall method. In the diary recall method, participants write down events in a diary during a specific time period. Later, memory for the events described in the dairy is tested. Typically, 
the time interval between the diary period and testing ranges from weeks to months (Rubin, 2005b; Thompson, 1982; Wagenaar, 1986). The diary records enable the researcher to control for the accuracy of the retrieved information with autobiographical information retrieved at test (Rubin, 2005b). An additional advantage of the diary recall method is that it can be used for single case studies (e.g., Wagenaar, 1986).

Two disadvantages are associated with the diary recall method. It has been demonstrated that events recorded in a diary may be thematically biased thus resulting in a non-representative selection of recorded events. Furthermore, because memories preceding and succeeding the diary recall period are not included in the retrieval of autobiographical information, the age distribution of events cannot be evaluated (Rubin, 2005b).

\section{Involuntary memory diary method}

Limited attention has been directed to involuntarily recollected events as compared to voluntarily recalled events. Involuntary retrieval is unintentional and triggered by external (e.g., olfactory sensations) or internal cues (e.g., thoughts). Research indicates that this form of retrieval is common and occurs on a daily basis (Berntsen \& Hall, 2004). Because involuntary memories are unintentionally recalled and retrieved sporadically, participants must be able to record events at any time (Berntsen \& Hall, 2004; Rubin, 2005b). Therefore, the diary format is an appropriate method for the investigation of involuntary memories. For example, Berntsen and Hall (2004) contrasted involuntarily retrieved events with word-cued events with regard to various dimensions such as specificity, emotionality, and physical reactivity. Results indicated that involuntary memories were experienced as more specific and less pleasant than word-cued memories. Furthermore, the participants also experienced stronger physical reactions to involuntary memories than wordcued memories.

As noted above, an advantage of the involuntary memory diary method is the investigation of events retrieved in a naturalistic context. However, because of the naturalistic nature of the retrieval condition there is limited control over the content and age of memories. In addition, the accuracy of the recalled memories cannot be evaluated. 


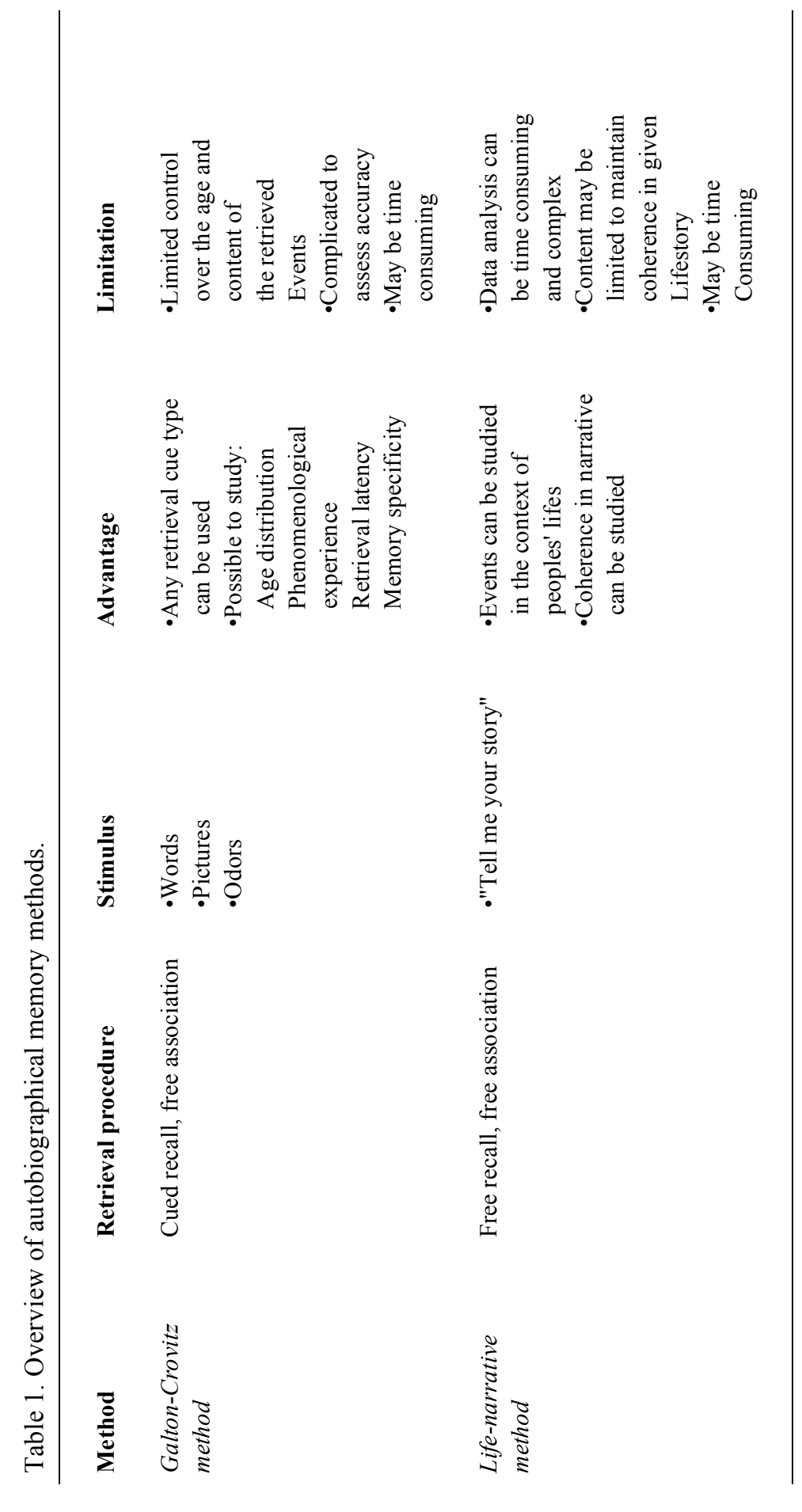




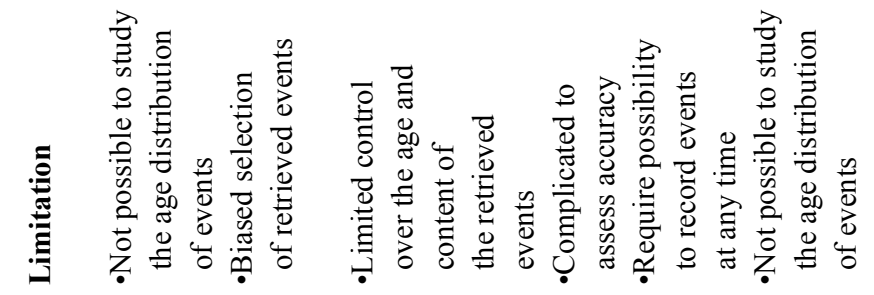

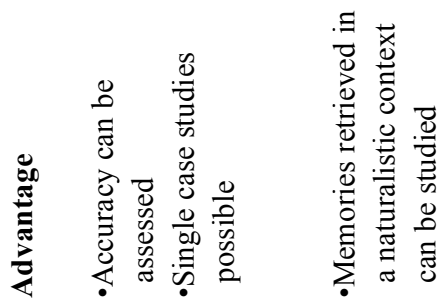

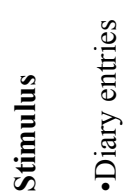

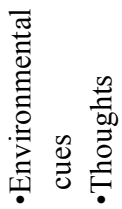

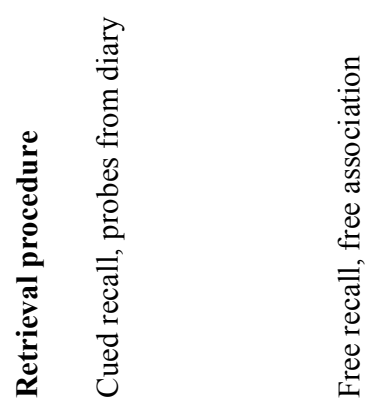

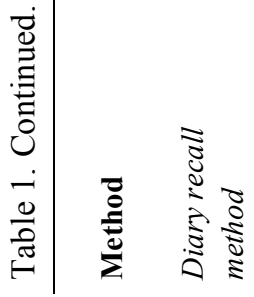

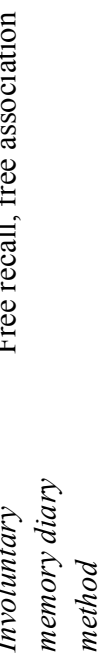




\section{Summary}

Several methods are available for the investigation of autobiographical memory. In the present section four methods were reviewed: the GaltonCrowitz method, the life-narrative method, the diary recall method, and the involuntary memory diary method.

\section{The age distribution of autobiographical memories}

A central topic of autobiographical memory research concerns the distribution of memories across the life-span. To investigate age distributions, participants retrieve memories and date them according to age at the occurrence of the event (i.e., age at event). Typically, the distribution of memories is obtained by dividing the life-span into intervals (e.g., 5- or 10-year intervals). The proportions of memories are calculated by dividing the number of retrieved memories in the respective time interval by the total number of retrieved events. It is well established that the age distribution of memories follows a specific pattern that includes three components: the childhood amnesia, the bump, and forgetting (Bruce et al., 2005; Conway \& PleydellPearce, 2000; Rubin, 1982; Rubin \& Schulkind, 1997b). The typical age distribution for word-cued memories is displayed in Figure 4.

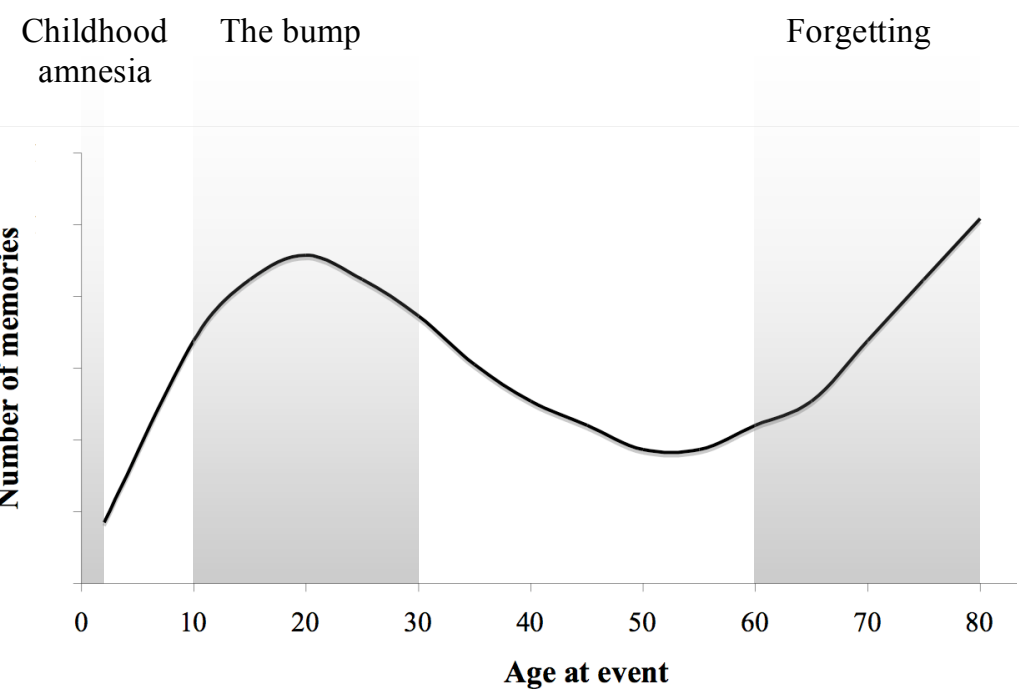

Figure 4. A schematic illustration of the age distribution of word-evoked memories. 


\section{The childhood amnesia}

As shown in Figure 4, the childhood amnesia comprises the first two years of the life-span. In general, events experienced before the age of two are not available for explicit recollection later in life (Conway \& Pleydell-Pearce, 2000; Newcombe, Drummey, Fox, Lie, \& Ottinger-Alberts, 2000). The childhood amnesia is a phenomenon reflecting the gradual development of the brain during the first years of life (Newcombe, Drummey, Fox, Lie, \& Ottinger-Alberts, 2000). Several explanations have been proposed for the childhood amnesia phenomenon: (a) socio-linguistic development (Fivush \& Nelson, 2004; Nelson \& Fivush, 2004), (b) lack of a cognitive self (Howe \& Courage, 1997; Wheeler, Stuss, \& Tulving, 1997), and (c) neurobiological development (Newcombe, Drummey, Fox, Lie, \& Ottinger-Alberts, 2000).

Nelson \& Fivush (2004) argued that the linguistic and social development is critical for the formation and organization of autobiographical memories. The socio-cultural developmental model postulates that memories are constructed through the interactions between various cognitive and social functions, such as declarative memory, language, self-concepts, and narratives. Before the age of 5 years, these abilities are not fully developed to support the storage and formation of autobiographical events. Language plays a key role in the narrative and social interaction and the model points out that the development of autobiographical memory corresponds temporally to language development. However, the view that language is critical for autobiographical memory is not supported uniformly by empirical evidence. For example, it has been suggested that the emergence of autobiographical memory is the result of a cognitive self and that language is a bi-product of memory development (Howe \& Courage, 1997; Wheeler, Stuss, \& Tulving, 1997). The cognitive self is a function that organizes information related to the individual (Howe \& Courage, 1997). Another proposed explanation is that childhood amnesia is related to the maturation of the prefrontal cortex (PFC) (Newcombe, Drummey, Fox, Lie, \& Ottinger-Alberts, 2000). An extensive number of studies have demonstrated that declarative memory, working memory, and executive function depend on the integrity of the PFC (e.g., Marklund et al., 2007; Ranaganath, Johnson, \& D'Esposito, 2003; Rugg, Fletcher, Chua, \& Dolan, 1999). Because the emergence of autobiographical memory corresponds to the maturation of the PFC it has been suggested that this brain region plays a key role in childhood amnesia (Newcombe, Drummey, Fox, Lie, \& Ottinger-Alberts, 2000).

\section{The bump}

A well-established finding in the domain of autobiographical memory is a peak (i.e., the bump) in the frequency of retrieved events in between the second and third decades of life. It has been found that the bump is most 
often observed for older adults and less often for persons under the age of 40 years (Berntsen \& Rubin, 2002; Rubin, Rahhal, \& Poon, 1998). The bump is rarely observable for younger adults because of the proximity of participants' age in relation to the bump location. For example, in a study by Rubin and Schulkind (1997a), word-cued age distributions for younger (20 years) and older adults (80 years) were investigated. For the older age cohort the bump was located to 10-20 years whereas no bump was observed for the younger group of participants.

Also, for individuals older than 40 years, the bump for the most vivid and important memories peak between 10-30 years for individuals approximately over 40 years (Rubin, Rahhal, \& Poon, 1998). On the basis of these findings, the authors concluded that things learned in early adulthood also are remembered the best. Further, the life-narrative (i.e., free recall) method also has been shown to yield an age distribution peak between the ages of 10-30 years. Both the Galton-Crowitz and the life-narrative methods produce a peak of retrieved memories in the adolescence and young adulthood. This pattern of observations provides strong support that the reminiscence bump is a real phenomenon. A summary of studies focusing on the location of the bump for autobiographical memories is provided in Table 2.

Rubin, Rahhal, and Poon (1998) provided four accounts of the bump; (a) cognitive, (b) developmental, (c) identity formation, and (d) evolutionary. According to the (a) cognitive account events from early adulthood is remembered better because many novel events and rapid changes occur during this period. The turbulent period of young adulthood is typically followed by relative stability in later adulthood. Thus, such distinct and consequential effects that are followed by stability will appear as more distinctive and more rehearsed than events from earlier and subsequent life periods and are as a consequence better remembered (Rubin, Rahhal, \& Poon, 1998). During childhood, cognitive abilities and neural substrates are gradually developing. During adolescence a range of cognitive functions, (e.g., episodic memory, executive functions) are developed to reach their maximum capacities. Thus, according to (b) the developmental account the bump is a result of a peak in performance and functionality of human cognitive abilities and its underlying neural substrates. Also, from (c) a personality perspective, identity formation may also play a role in the generation of the memory bump. The idea here is that events that contribute and shape one's identity also will increase the likelihood of subsequent recollection. Last, (d) evolution may influence the bump by influencing psychological mechanisms in order to increase genetic fitness. Thus, it is not the psychological mechanisms per se that produces the bump but underlying evolutionary processes. 


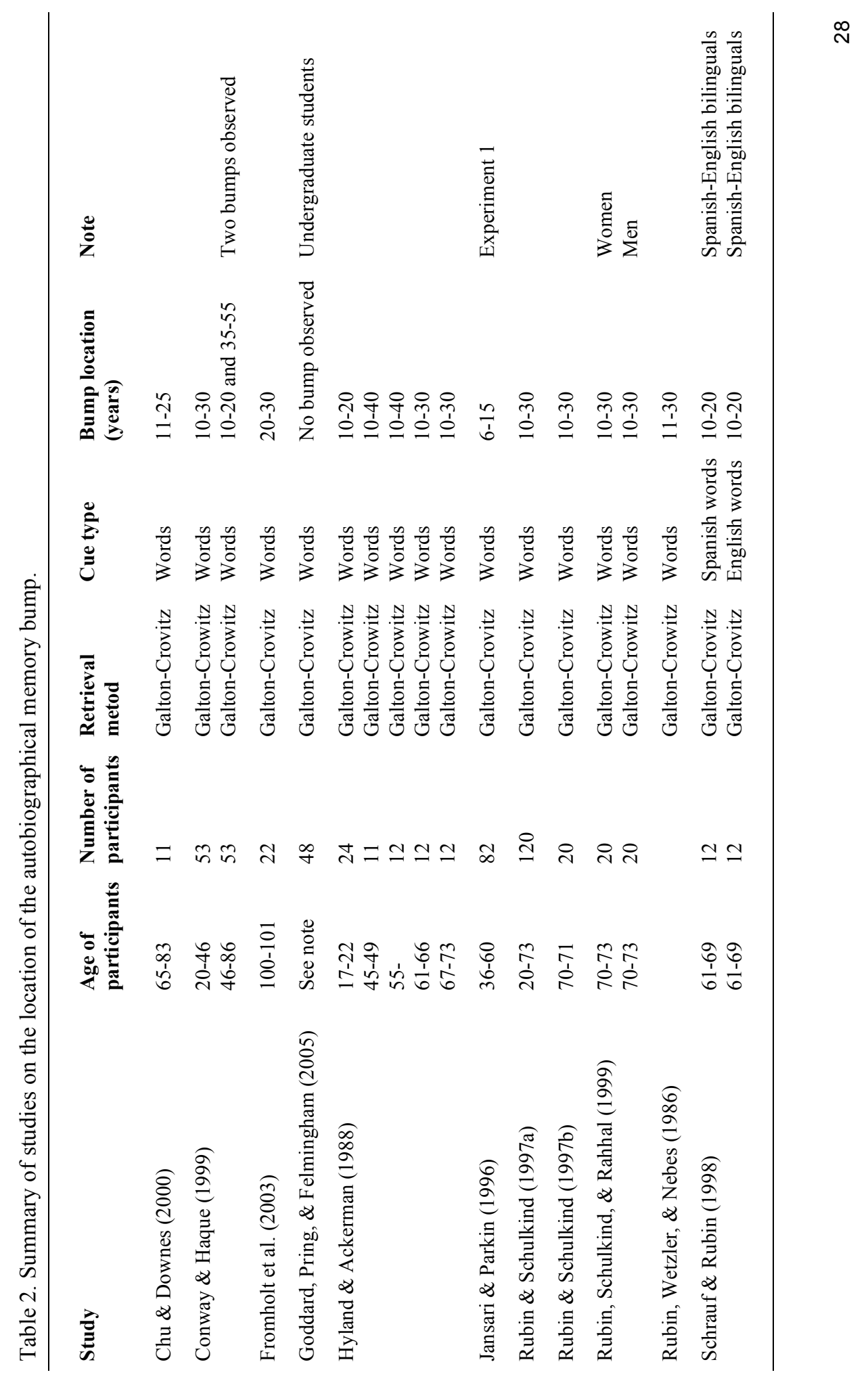




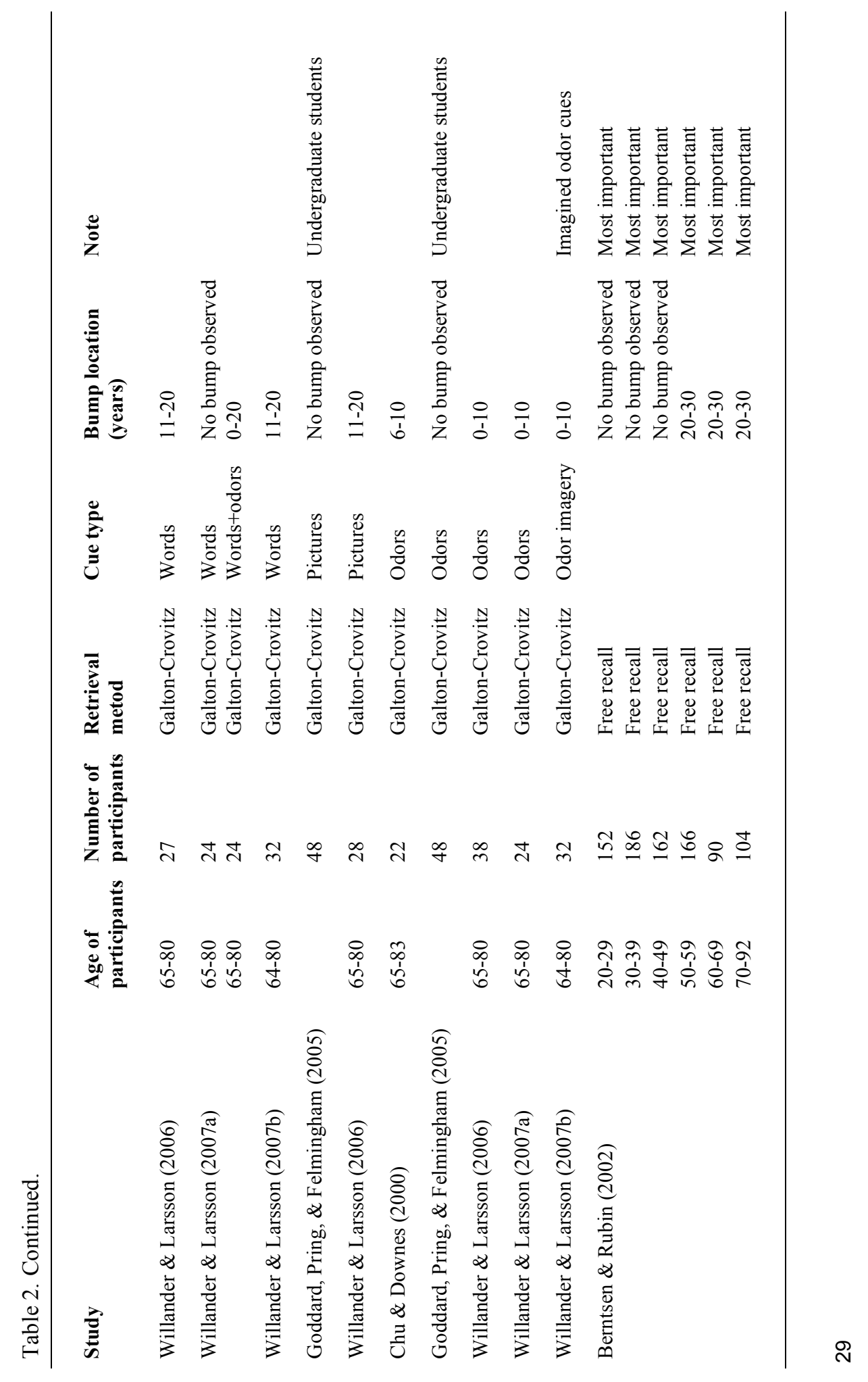




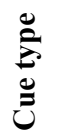

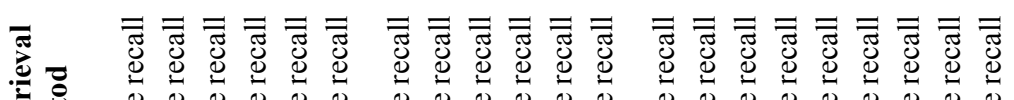

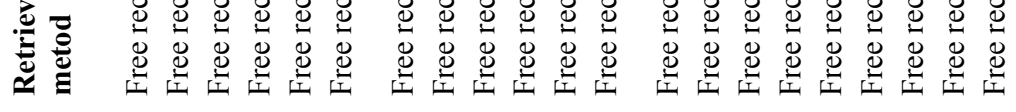
官

言䆤

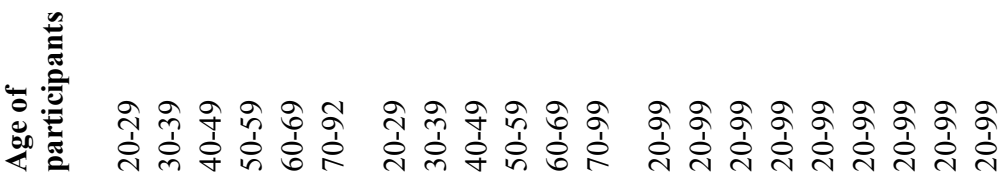



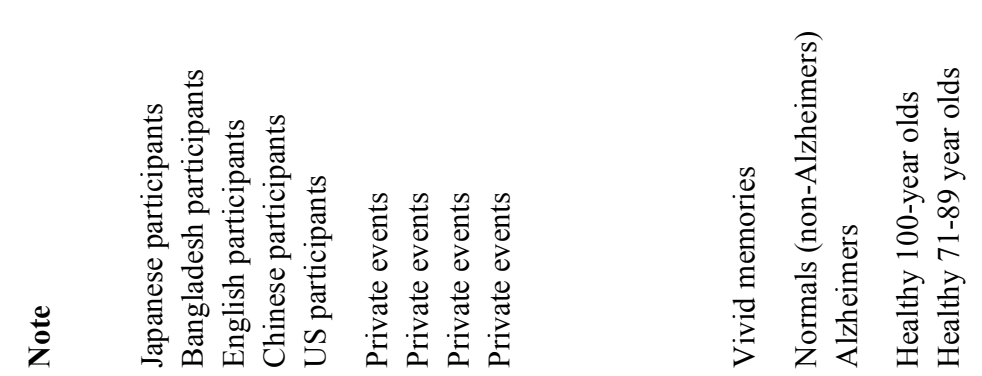

莺

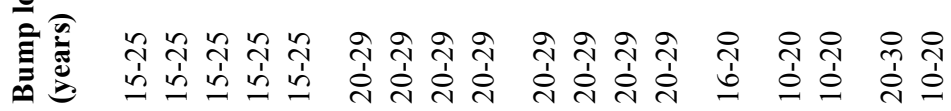

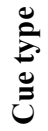

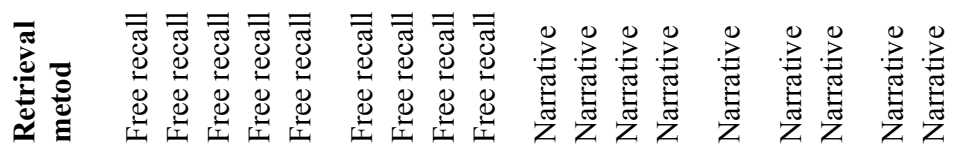
它

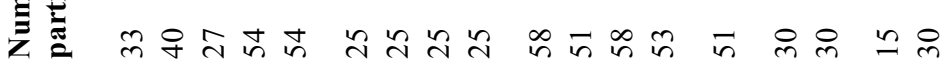

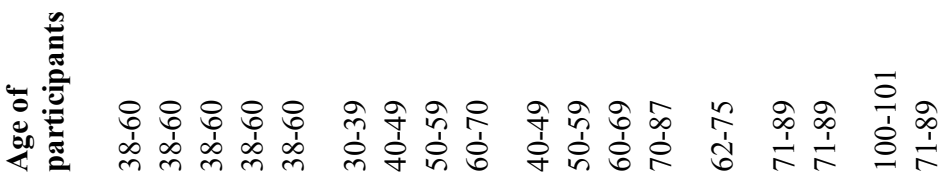

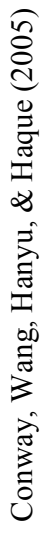

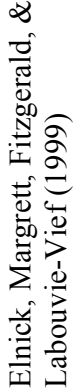

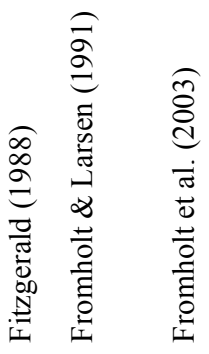




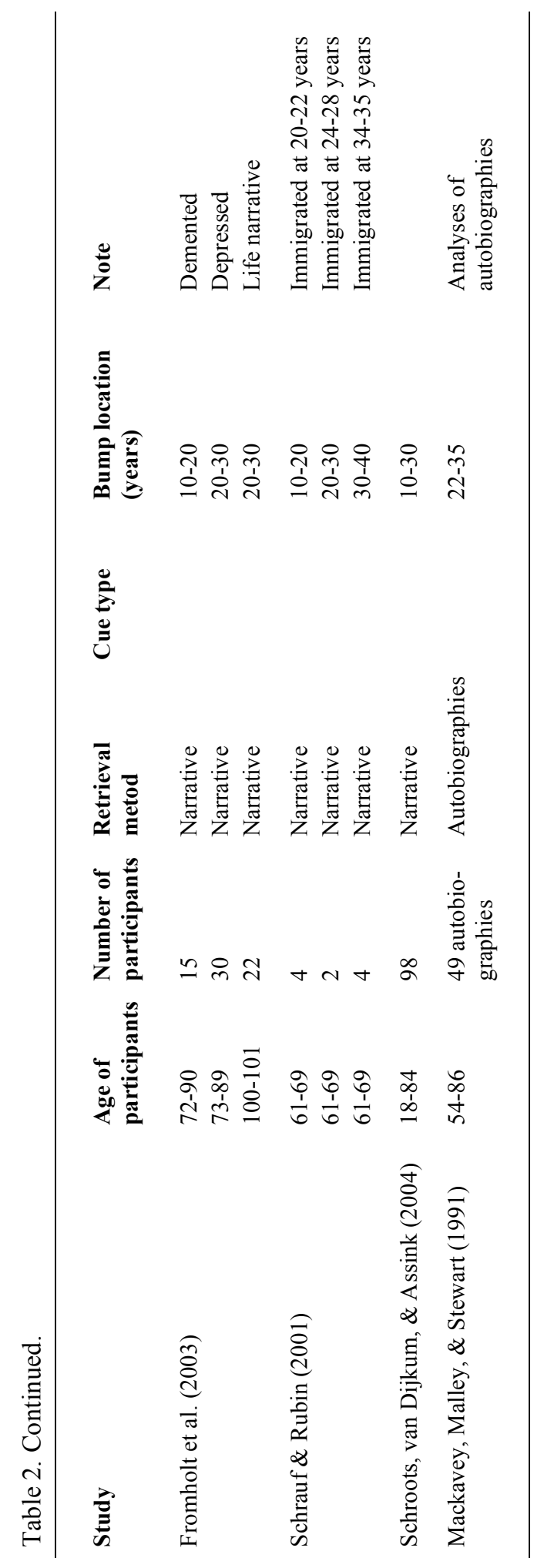




\section{Forgetting}

The third component in the age distribution of autobiographical memories is forgetting. Forgetting or the recency effect, is manifested as a decrease in the number of retrieved events as a function of the time since the remembered event occurred (Conway \& Pleydell-Pearce, 2000; Ebbinghaus, 1913; Rubin, 1982; Rubin \& Wenzel, 1996). Thus, accessibility drops with the passage of time. Conway and Pleydell-Pearce (2000) suggested that forgetting of the most recent 20-30 years may be related to the degree of self-relevance of the experienced information. As new autobiographical information is acquired some older information may become less important and loose relevance for the individual. Autobiographical knowledge with limited self-relevance will become less rehearsed and as a consequence the likelihood of forgetting will be larger (Conway \& Pleydell-Pearce, 2000).

\section{Summary}

The age distribution of autobiographical memories follows a specific pattern comprising three components: childhood amnesia, the bump, and forgetting. Childhood amnesia reflects the inability to recall events experienced during the first 24 months of life. For word-cued memories, a peak (i.e., the bump) in the number of retrieved events can be observed between 10-30 years of age. Forgetting reflects a decrease in the number of retrieved events as a function of the time since the remembered event occurred.

\section{Phenomenological aspects in autobiographical memory}

Recollection of personal events is a multimodal process (Rubin, 2006). It involves phenomenological experiences, such as imagery, emotions, and perceptual qualities (Markowitsch, Vandekerckhove, Lanfermann, \& Russ, 2003; Rubin, 2005a, 2006). Phenomenological experience may be defined as the subjective and conscious experience of the recollection process (Larsen, 1998).

In autobiographical memory research, retrieved information is often evaluated on various phenomenological dimensions. Research suggests that phenomenological experiences in memory recollection can be organized into two different categories: content qualities and appearance qualities (Larsen, 1998). Examples of content and appearance qualities are given in Table 3. 
Content qualities comprise phenomenological dimensions that relate to previously experienced events (Larsen, 1998). The content category comprises two subcategories: perceptual and reflective qualities. In the terminology of Conway and Pleydell-Pearce (2000) perceptual qualities are event-specific knowledge. Examples of perceptual qualities are sensory information such as visual imagery and auditory information. For example, a recollection may entail a visual image of the event but may also involve auditory information (e.g., a particular song). Another factor related to recollection of autobiographical memories is the point of view or vantage point (Georgia \& Neisser, 1983; McIsaak \& Eich, 2002, 2004). Vantage point comprises two modes of recollection; field and observer (Robinson \& Swanson, 1993). In the field perspective, the event is re-experienced as it was seen through the eyes of the rememberer. In contrast, in the observer mode the rememberer takes the perspective of a spectator (Georgia \& Neisser, 1983). Memories categorized as field memories have been shown to be more emotional than memories with an observer mode. However, observer memories carry more information about object location and physical appearance than field perspective memories (McIsaak \& Eich, 2002). Interestingly, Robinson and Swanson (1993) reported that shifting perspective from field to observer decreased the experienced emotionality of the events. However, no change in emotionality was detected when the perspective was shifted from observer to field.

The second subcategory concerns reflective qualities. Reflective qualities are cognitive and experiential evaluations of retrieved events (Larsen, 1998). The reflective category comprises qualities such as intentions, thoughts, and self-awareness (Larsen, 1998).

The appearance qualities are defined by the experience of the event during recollection. The appearance qualities can be divided into two subcategories: surface and belief qualities (Larsen, 1998). Surface qualities comprise experiential qualities related to evaluations of the mental image of the event, such as vividness, clearness, and amount of details. The second subcategory of appearance qualities is belief qualities. Belief qualities are phenomenological experiences related to judgments of the retrieved events. Typical belief qualities are remember/know, familiarity, and confidence. 
Table 3. Phenomenological experiences in autobiographical memory (adapted from

Larsen, 1997). Qualities in bold face are included in Study I-III of the present thesis.

\begin{tabular}{|c|c|c|c|}
\hline \multicolumn{2}{|c|}{ Content qualities } & \multicolumn{2}{|c|}{ Appearance qualities } \\
\hline Perceptual qualities & Reflective qualities & Surface qualities & Belief qualities \\
\hline $\begin{array}{l}\text { Sensory experience } \\
\text { Visual } \\
\text { Auditory } \\
\text { Olfactory } \\
\text { Taste } \\
\text { Tactile } \\
\text { Vantage point } \\
\text { Field } \\
\text { Observer }\end{array}$ & $\begin{array}{l}\text { Valence (pleasantness) } \\
\text { Intensity } \\
\text { How often thought of } \\
\text { Importance } \\
\text { Positive/negative } \\
\text { Brought back } \\
\text { Proud } \\
\text { Happy } \\
\text { Satisfied } \\
\text { Calm } \\
\text { Excited } \\
\text { Amused } \\
\text { Surprised } \\
\text { Anxiousness } \\
\text { Relieved } \\
\text { Bored } \\
\text { Embarrassed } \\
\text { Annoyed } \\
\text { Lonely } \\
\text { Afraid } \\
\text { Guilty } \\
\text { Disgust } \\
\text { Dissapointed } \\
\text { Ashamed } \\
\text { Jealous } \\
\text { Love } \\
\text { Traumatic }\end{array}$ & $\begin{array}{l}\text { Details } \\
\text { Vividness } \\
\text { Clearness }\end{array}$ & $\begin{array}{l}\text { Familiarity } \\
\text { Remember/know } \\
\text { Confidence }\end{array}$ \\
\hline
\end{tabular}




\section{The feeling of being brought back in time}

Fundamental to the re-experience of autobiographical events is the sensation of mental time travel (Tulving, 2000, 2002). Research suggests that phenomenal characteristics influence the sense of mental time travel, such that increased levels of sensory imagery and clearness in the recollection produce stronger feelings of traveling in time (D'Argembeau \& Van der Linden, 2004, 2006). In the experimental protocol, mental time travel is typically assessed by ratings of the feeling of being brought back in time to the occurrence of the event.

\section{Emotionality}

At a basic level, two subcategories of emotionality can be distinguished: pleasantness and intensity (Lang, Bradley, \& Cuthbert, 1999). For example, emotion (e.g., unpleasantness) can produce tunnel vision in recollection of traumatic events resulting in an emotionally driven attention (Berntsen, 2002). Moreover, pleasant memories hold more self-reported sensory details (visual, olfactory, and taste) than unpleasant or neutral events (D'Argembeau, Comblain, \& Van der Linden, 2003). It has been suggested that the underlying mechanism for this observation is a higher rehearsal for pleasant than unpleasant events. Also, evidence indicates that unpleasant emotions in autobiographical memories are forgotten faster (i.e., the fading affective bias) than pleasant emotions, supporting the view that pleasant events are processed differently than are unpleasant ones (Ritchie et al., 2006; Walker, Skowronski, Gibbons, Vogl, \& Thompson, 2003; Walker, Vogl, \& Thompson, 1997). This conclusion is further supported by data indicating that the bump is preserved for positive memories whereas it is absent for negative events (Berntsen \& Rubin, 2002). Thus, evidence suggests that processing of positive and negative events differ in autobiographical memory. Altogether these findings highlight the importance of dissociating between emotional states in the evaluation of autobiographical memory.

\section{Summary}

Phenomenological experiences are subjective evaluations of event recollections. Evaluations can be done across different dimensions that include content and appearance qualities. 


\section{Higher-order olfactory processing}

\section{Odor memory}

Modest efforts have been devoted to the construction of a theoretical framework that may elucidate the various expressions olfactory memory (Larsson, 2002; Larsson \& Melinder, 2007). Most likely this is due to that the scientific interest for odor memory has been relatively small. To date, research on human olfactory memory has mainly been oriented towards declarative forms, whereas implicit aspects of odor memory have been neglected to a large extent (Larsson \& Melinder, 2007; Olsson \& Fridén, 2001). Two different memory systems are defined as declarative: episodic and semantic memory. With regard to the semantic memory system, evidence suggests that common olfactory processes such as odor identification, perceived hedonics, and familiarity draw on semantic memory functions. Episodic memory is involved in the recognition of an odor experienced at a previous occasion, or when an odor activates a memory representation (Larsson, 2002).

Because odors are present in most natural contexts, associations between olfactory information and events are highly probable. The encoding specificity principle states that memory is enhanced when conditions present during retrieval match those that were present during encoding (Tulving \& Thomson, 1973). Following this principle, odors that are integrated with a specific event may serve as a potential cue or trigger for evoking all, or parts of, a specific target episode. Indeed, research on odors as context-dependent cues has shown that reinstatement of olfactory information that was present at encoding and retrieval may enhance memory performance (Aggleton \& Waskett, 1999; Cann \& Ross, 1989; Herz, 1997a, 1997b; Pointer \& Bond, 1998). For example, Schab (1990) investigated the effects of ambient odors on episodic memory by providing participants with an ambient odor (i.e., chocolate) while they studied a list of words. The experiment was a 2 (odor at encoding, or no odor at encoding) x 2 (odor at retrieval, no odor at retrieval) between-subjects design. 24 hours later, subjects were asked to recall as many of the words as possible. The results showed that the group that was re-exposed to the odor during retrieval remembered more words than the other groups. This finding suggests that the encoding specificity principle also may be generalized to olfactory information. 


\section{Retention of olfactory information}

Evidence is yet sparse regarding the longevity of olfactory information. Olfactory forgetting has mainly been studied for shorter retention intervals ranging between minutes to days (Larsson, 1997) with only a few exceptions (e.g., Engen \& Ross, 1973; Goldman \& Seamion, 1992). In an early study, Engen and Ross (1973) assigned participants to one of four odor encoding groups, with the following retention intervals: immediate testing, 24 hours, 7 days, and 30 days. The results indicated that odor recognition performance was higher for participants tested 24 hours after encoding than those tested 30 days later. Importantly, recognition performance did not differ between any other of the retention intervals, suggesting that long-term episodic odor memory may not be susceptible to forgetting. This is a remarkable finding considering information encoded by other modalities other modalities (i.e., vision and audition), demonstrate substantial loss for both recall and recognition over time (e.g., Ebbinghaus, 1913; Rubin \& Wenzel, 1996). However, others have failed to replicate the lack of olfactory forgetting. Perkins and McLaughlin Cook (1990) assessed odor recognition and recall (i.e., odor identification) at two points in time, immediately after and one week after encoding. The results indicated that for the odor recognition condition participants that were tested immediately after encoding performed better than the group tested one week after encoding. For the recall task (i.e., odor identification), no difference in performance between the immediate and one week testing groups was observed (Perkins \& McLaughlin Cook, 1990).

Although olfactory information may demonstrate limited forgetting over time, it is worth noting that overall memory performance for olfactory information is lower than information associated with other sensory systems. Lawless (1978) compared recognition memory for complex figures, simple figures, and odors over a retention interval comprising four months. The results indicated that overall recognition was higher for complex figures than simple figures and odors, although the latter two also indicated retention over time.

Another way of elucidating retention functions for odors is to study memory for odors in a naturalistic context. Case studies may provide valuable information. Larsson and Melinder (2007) reported of a 35-year old refugee (SN) that had sought psychiatric treatment for olfactory aversions. The patient described how he as a young boy came into contact with dead bodies and rotten corpses in a war. As a soldier, he was forced to carry these rotten corpses that carried a hideous smell. Years later, SN began to develop meatinduced aversions that originated from his traumatic past. Although odor aversions tap into conditionalized responses (i.e., implicit memory) it provides an interesting illustration of the potential strength of olfactory representations and associations over longer time intervals. 


\section{Semantic processes in olfaction}

Early research focusing on the relationship between semantic processing and episodic odor memory revealed little or no influence of verbal knowledge on memory performance. For example, Engen and Ross (1973) studied episodic recognition performance for odors that were encoded in conjunction their respective names or without verbal descriptors. The results indicated no difference in episodic recognition performance between the two conditions. However, later work has clearly demonstrated an influence of semantic processes on a number of olfactory tasks, such as episodic recognition (Larsson \& Bäckman, 1993, 1997), odor naming (Larsson \& Bäckman, 1993), familiarity (Distel \& Hudson, 2001), and hedonic evaluations (Herz, 2003; Herz \& von Clef, 2001). For example, Larsson and Bäckman (1993) examined odor recognition following one of three encoding conditions: name-only, odor-only, or odor-name. Notably, recognition was affected by encoding condition, such that memory performance was higher in the odorname condition than in the name-only and odor-only conditions. In a similar vein, Herz and von Clef (2001) observed higher positive ratings in intensity, pleasantness, and familiarity when identical odors were presented with a positive label (e.g., parmesan cheese) than a negative label (e.g., vomit). Likewise, Distel and Hudson (2001) showed that intensity, pleasantness, and familiarity ratings increased when odor evaluations were performed in conjunction with a verbal descriptor as compared to an odor-only condition.

\section{Summary}

Sparse evidence suggests that episodic retention of olfactory information may show a flatter forgetting function (i.e., less forgetting over time) than retention for visual or verbal information. Also, available evidence indicates that semantic knowledge of odors influences both olfactory perception and memory proficiency.

\section{Odor imagery}

Imagery is defined as the capability to evoke mental images in the absence of external stimuli (Kosslyn, Ganis, \& Thompson, 2001; Stevenson \& Case, 2005). Imagery is well established for the visual and auditory domains (Halpern \& Zatorre, 1999; Kaski, 2002; Sheehan, 1967b, 1971; Zatorre, 2005). However, the existence of olfactory imagery has been debated and some researchers have suggested that humans are not capable of forming olfactory images (Herz, 2000). Yet, support for olfactory imagery is available from a number of different methods, such as volitional imagery, olfactory hallucinations, dreams, and functional neuroimaging (Arshamiam, Willander, \& Larsson, 2007; Bensafi et al., 2003; Carrasco \& Ridout, 1993; 
Djordjevic, Zatorre, Petrides, Boyle, \& Jones-Gotman, 2005; Stevenson \& Case, 2004, 2005).

Volitional imagery. The evocation of mental pictures by free will is referred to as volitional imagery (Stevenson \& Case, 2005). This form of imagery is investigated by phenomenological experiences associated with generated mental pictures, such as reports of vividness, clearness, and details. Typically, volitional imagery is evaluated in questionnaires using self-ratings, such as the Volitional Visual Imagery Questionnaire (VVIQ; Marks, 1973) and the Volitional Olfactory Imagery Questionnaire (VOIQ; Gilbert, Crouch, \& Kemp, 1998). Because olfactory imagery representations are more difficult to evoke than visual and auditory images, evidence for real volitional odor imagery has been equivocal. Also, evidence suggests that mental representations of odors are experienced as less vivid than images from other modalities (e.g., vision, audition) (Ashton \& White, 1980; Sheehan, 1967a). Although it is well documented that odors are more difficult to imagine than information from other sensory modalities, it should be noted that most of the odor imagery studies are based on aggregated group data. Recent findings suggest a large inter-individual variation in the ability to produce olfactory images (Bensafi \& Rouby, 2007).

Olfactory hallucinations. A major source of evidence in support of olfactory imagery comes from research on hallucinations. Odor imagery experiences as a result of olfactory hallucinations have been observed in various clinical disorders such as schizophrenia, epilepsy, and post-traumatic stress disorder. Reviewing clinical evidence, Stevenson and Case (2005) estimated that the prevalence of olfactory hallucinations in schizophrenics range between 2$35 \%$ indicating that olfactory hallucinations may not be a rare condition. The olfactory experiences in schizophrenic olfactory hallucinations are typically diffuse but highly emotional. For epilepsy, the prevalence of olfactory hallucinations has been estimated to range between 1-30\% (Stevenson \& Case, 2005). Epileptic olfactory hallucinations usually occur prior to seizures. olfactory hallucinations resulting form epilepsy are often experienced as unpleasant and may also trigger stimuli-oriented actions (e.g., evacuating a building due to an hallucination of a smell of fire; Hausser-Hauw \& Bancaud, 1987; Stevenson \& Case, 2005).

Olfactory dreams. Although dreams have the potential to provide a source of knowledge regarding the nature of odor imagery, few studies have explicitly addressed olfactory experiences in dreams. Sparse evidence suggests that olfactory dream content is more emotional but less vivid than visual dream imagery (Stevenson \& Case, 2005). Also, a positive relationship between odor identification performance and prevalence of olfactory experiences in dreams has been reported (Stevenson \& Case, 2005). This observation was recently replicated and extended by Arshamiam, Willander, and Larsson 
(2007), who showed that individuals who experienced odors in dreams and scored high in odor interest and volitional odor imagery also outperformed a group of non-olfactory dreamers in olfactory behavioral measures. Specifically, no difference between groups was observed in odor threshold but the olfactory dreamers showed better episodic odor recognition performance and identified more odors than the group who never experienced any chemosensory dream content. Taken together, these observations suggest a relationship between the prevalence of mental olfactory representations and behavioral performance.

Neuroimaging evidence. Brain activation studies focusing on visual and auditory imagery have consistently demonstrated that the brain regions involved in perceptual processing of information from the respective sensory system also are involved in imagery processes (Halpern \& Zatorre, 1999; Kosslyn, Ganis, \& Thompson, 2001; Roland \& Gulyás, 1995; Zatorre, 2005). For example, activations of primary visual cortex have been observed for visual imagery and areas in primary auditory regions have been shown to become activated during auditory imagery (Halpern \& Zatorre, 1999; Kosslyn, Ganis, \& Thompson, 2001; Roland \& Gulyás, 1994, 1995; Zatorre, 2005). Djordjevic et al. (2005) investigated olfactory imagery with PET. The results indicated that brain regions involved in perceptual processing of olfactory information (e.g., the primary olfactory cortical region) also were activated during olfactory imagery. Thus, available evidence suggests a neuroanatomical overlap between perceptual processing and mental evocation, a relationship that seems to be present across modalities.

\section{Summary}

The overall pattern of findings obtained from a range of different domains (e.g., hallucinations, dreams, neuroimaging) provides support for the existence of olfactory imagery. However, olfactory imagery is less frequent and more difficult to evoke than visual or auditory imagery. 


\section{Autobiographical odor memory}

In $D u$ coté de chez Swann, Proust (1919) described the recollection of a vivid and emotional childhood event that was evoked by the taste/smell of a Madeleine cookie. Based on this description the proustian phenomenon has been used to denote the hypothesis that odors evoke older, more emotional, and vivid memories than information evoked by other cue types. Until recently, support for the proustian phenomenon has mostly relied on anecdotal sources. Scientific evidence is yet scarce regarding the nature of autobiographical odor memory. Although research has focused on memory for odors, most of these efforts concern episodic memory for a set of odors over time (e.g., odor recognition, see above) rather than the potential of an odor to evoke a specific autobiographical event. There are three lines of support: life-span distributions of memories, phenomenological experiences, and the potency of odors to evoke memories.

\section{The age distribution of autobiographical odor memories}

In a study addressing the age distribution of odor-evoked memories, Chu and Downes (2000) tested 22 older adults (mean age 69.4 years; age range 6583 ) in an autobiographical odor memory task, and an additional 11 older adults in a label task (i.e., odor names). The experimental procedure was based on the Galton-Crowitz method. Thus, participants were presented with odors or words and asked to relate any autobiographical event related to the respective cue. The stimuli materials consisted of common odors such as wine, soap, clove, cinnamon, rose, and petrol. In instances of retrieval, the participants provided brief descriptions of the events. After the retrieval phase, the events were dated according to the participants age-at-event. To enable analysis of the age distributions, the life-span was segmented into five-year intervals (i.e., 6-10, 11-15, 16-20), for which the proportions of memories were calculated. The results indicated that the bump for memories evoked by odors was located to the 6-10 year interval as compared to labelcued events that peaked between 11-20 years. These findings suggest that odors evoke older memories than word cues. However, it is worth highlighting that a limitation of the Chu and Downes (2000) study was that the reported age distribution only comprised the first 35 years of the life-span. 
Following up on these results, Goddard, Pring, and Felmingham (2005) investigated the distribution of odor-evoked memories for a sample of younger adults (mean age 24.54 years). Here, each participant was presented with three cue types, i.e., words, pictures, and odors. With some minor exceptions, the stimuli materials were similar to that used by $\mathrm{Chu}$ and Downes (2000). In instances of retrieval, memories were briefly described and rated on vividness. Dating of events followed after the retrieval phase. Because of the participants' young age, memories were coded as childhood, recent, or other. The category of childhood memories constituted events occurring in the first decade of life $(<10$ years) whereas recent events were defined as those that had occurred within the last year. Finally, memories not categorized as childhood or recent were classified as others. The results showed that most of the retrieved events had occurred within the last year irrespective of the cue type. However, it is worth noting that a visual inspection of the data suggests that odors seemed to evoke more childhood memories than words or pictures although this pattern was not supported by the statistical analyses. Likewise, Rubin, Groth and Goldsmith (1984) did not find any difference in the age distributions for word- and odor-evoked autobiographical memories in a group of undergraduate students. Thus, available evidence suggests that the olfactory bump is not observable for younger cohorts whereas it is for older cohort samples.

\section{Phenomenological experience in odor-evoked memories}

Autobiographical odor memories have been characterized on a number of experiential dimensions, such as pleasantness, vividness, and the feeling of being brought back in time to the occurrence of the event. Typically, odor triggered events are compared to word-evoked memories, although comparisons with other cue types (e.g., pictures) also have been done.

A central aspect of autobiographical odor memory is emotion (Herz \& Cupchik, 1995; Herz \& Schooler, 2002). Because of the direct synapsing from the olfactory bulb to the amygdala it has been proposed that autobiographical odor memories are more emotional than memories evoked by other cue types. The fundamental role of amygdala in emotional processing of memories have been demonstrated in a number of studies (e.g., Cahill, Babinsky, Markowitsch, \& McGaugh, 1995; Cahill et al., 1996; Canli, Zhao, Brewer, Gabrieli, \& Cahill, 2000).

Investigating the effects of emotionality on episodic odor memory, Herz and Cupchic (1995) used a paired-associate paradigm. Participants were pre- 
sented with either neutral or emotional paintings in conjunction with words or odors and tested 48 hours later on their memory for the paintings in a recall task. Results indicated that the odor cues evoked more emotional materials than words. Likewise, comparing olfactory, visual, and auditory cues, Herz (2004) demonstrated that odors produced more emotional memories than the other cues types. In Herz (2004), 70 participants ranging from 7-79 years were presented with three verbal labels (i.e., popcorn, grass, or campfire) and asked to retrieve autobiographical memories associated with these labels. After presentation, participants were re-exposed to the retrieved events and asked to recall additional information in conjunction with the same three cues. However, in the re-exposure phase, cues were not verbal but presented either as cue congruent odors, pictures, or sounds. The results indicated that autobiographical information retrieved in conjunction with odors was experienced as more emotional than information retrieved by the pictures or sounds (Herz, 2004). The olfactory advantage in retrieval of emotional autobiographical memories is further supported by neuroimaging evidence. Herz, Eliassen, Beland, and Souza (2004) investigated brain activation patterns for autobiographical memory evoked by odors and pictures. Stronger activations of the amygdala and the hippocampus were found for odor-associated memories than for visually evoked events.

With regard to the experience of mental time travel associated with the recollection of events, Herz and Schooler (2002) found stronger feelings of being brought back to the occurrence of the events for odor-evoked events than for memories evoked by words. Interestingly, no difference in mean age was observed between the word and odor conditions, suggesting that the feeling of being brought back in time may not be associated with the age of retrieved events.

According to the proustian hypothesis, odors also carry the potential to evoke more vivid and detailed memories than other modalities. Herz and Schooler (2002) compared memories evoked by olfactory or verbal cues. The results showed that autobiographical odor information was experienced as more vivid than memories evoked by verbal labels. However, in a later study, Herz (2004) was unable to replicate these observations, yielding a mixed pattern of results regarding experienced vividness of olfactory evoked autobiographical information.

\section{The efficiency of odors as cues to autobiographical memories}

The proustian hypothesis postulates that odors are more potent cues to autobiographical memories. However, a review of the available evidence shows 
that this statement is not substantiated by experimental research. For example, Rubin, Groth, and Goldsmith (1984) contrasted the number of memories evoked by words, odors, and pictures. In Experiment I, and for an equal number of participants, words evoked a total of 279 events (out of 300 possible), whereas odors evoked 266 events (out of 300 possible). In a second experiment, words evoked 489 events (out of 576 possible), pictures 501 events (out of 576 possible), and odors 377 events (out of 464 possible). Likewise, Chu and Downes (2000) observed that a sample of 22 participants evoked an equal number of memories $(n=242)$ when presented with odors as a group of 11 participants that were presented with words $(n=247)$. Furthermore, Goddard, Pring, and Felmingham (2005) demonstrated that odor cues produced fewer memories than did words and pictures. In addition, retrieval latencies were longer in the odor cue condition than the word and picture cue conditions. Taken together, the overall pattern of findings suggest that odors are not more efficient retrieval cues of autobiographical memories with regard to the number of elicited memories and retrieval latencies.

\section{Summary}

The scarce evidence suggests that odors evoke older and more emotional memories than other cue types. Also, odor-evoked memories are associated with stronger feelings of being brought back in time to the occurrence of the event. However, odors are less efficient as autobiographical memory cues with regard to the number of evoked events and retrieval latencies. These findings suggest that odor cues may be more event-specific than verbal and visual cues. 


\section{Overview of empirical studies}

\section{Study I}

Willander, J., \& Larsson, M. (2006). Smell your way back to childhood: Autobiographical odor memory. Psychonomic Bulletin \& Review, 13(2), 240-244.

\section{Aim}

The aim of Study I was to investigate potential influences of cue type (words, pictures, odors) in the retrieval of autobiographical memories with regard to: (a) whole life-span age-distributions, (b) phenomenological experiences (e.g., emotionality, vividness, the feeling of being brought back), and (c) the number of retrieved memories.

\section{Background}

The age distribution of verbally evoked autobiographical memories is well studied and demonstrated to peak between 10-30 years of age (Rubin, Rahhal, \& Poon, 1998). However, the age distribution of odor-evoked autobiographical memories has received only limited attention. A seminal study found that the bump of the odor-evoked age distribution was located to the first decade of life (6-10 years) (Chu \& Downes, 2000). However, a limitation of that study was the small sample size $(n=22)$ and that the reported age distribution only included the first 35 years. With regard to phenomenological experiences, odor-evoked memories have been reported to be more emotional than memories evoked by other stimuli (Herz \& Cupchik, 1995; Herz $\&$ Schooler, 2002). Also, olfactory evoked information has been described as more vivid and associated with a stronger feeling of being brought back in time. Thus, the main aims of Study I were to investigate (a) whole life-span age distributions across three sensory cue types (word, picture, odor), and (b) phenomenological experiences as a function of cue type (word, picture, odor) in a larger sample of healthy older adults. 


\section{Design}

The basic design was a 3 (Cue type: word, picture, odor) x 8 (Decade) mixed factorial design where the first factor was a between-group factor and the second a within-group factor.

\section{Method}

Ninety-three healthy participants (53 women and 40 men; mean age 74.3; age range 65-80 years) were recruited from senior-citizen organizations in the Stockholm area and randomly assigned to one of three cue conditions (word, picture, or odor). The participants were presented with 20 cues (e.g., cinnamon, tar, chlorine, clove) and asked to relate any autobiographical event for a given cue. Thirty seconds were allowed for retrieval. At the end of the experiment, all retrieved memories were rated on eleven experiential scales (e.g., pleasantness, intensity, the feeling of being brought back in time, and vividness) and subsequently dated.

\section{Results}

The results indicated that memories evoked by odors were older than memories evoked by words and pictures (see Figure 5). The bump of the olfactory evoked age distribution was located to the first decade of life (i.e., $\leq 10$ years of age), whereas the bump of the word- and picture-evoked age distributions peaked in the second decade (i.e., 11-20 years of age). With regard to phenomenological experience, memories evoked by odors were associated with stronger feelings of being brought back in time to the occurrence of the event than the word- and picture-evoked memories, whereas word- and picturecued events did not differ. Picture-evoked events were experienced as more emotional at the occurrence of the event than memories evoked by words or odors but no difference was observed between word- and odor-evoked events. Picture-evoked events were also thought of more often than memories evoked by words or odors, whereas no significant difference between the latter two was observed. Finally, with regard to the number of evoked memories, words, pictures, and odors evoked an equal amount of autobiographical events. 


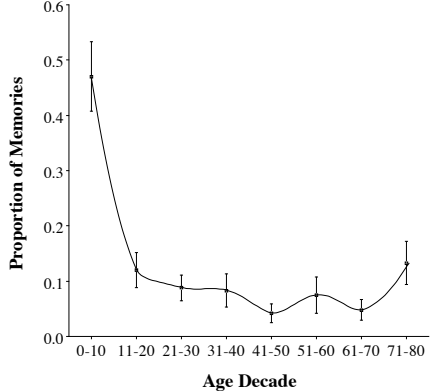

(a)

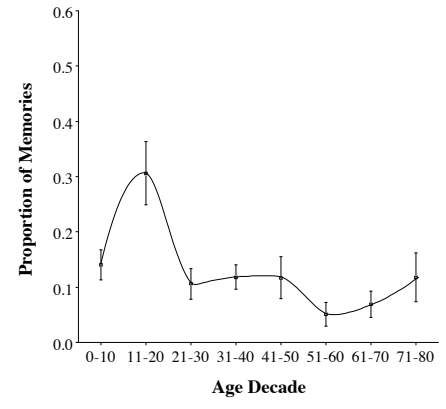

(b)

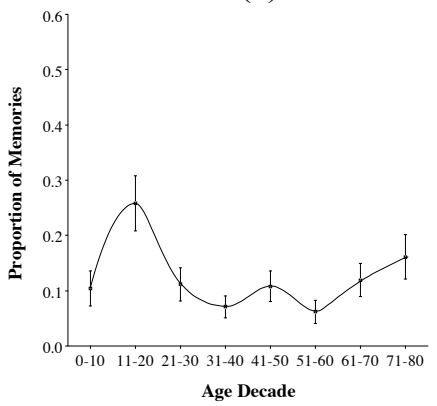

(c)

Figure 5. The distribution of (a) odor-, (b) word-, and (c) picture-evoked autobiographical memories across the life-span. Error bars indicate \pm 1 standard error.

\section{Conclusion}

The main conclusions from Study I were that (a) odors evoke older memories than words and pictures, and that (b) events triggered by odors produce stronger feelings of being brought back in time than events evoked by words, and (c) word- and odor-evoked events are thought of less often than events evoked by pictures. 


\section{Study II}

Willander, J., \& Larsson, M. (2007). Olfaction and emotion: The case of autobiographical memory. Memory \& Cognition, 35(7), 1659-1663.

\section{Aim}

The main aims of Study II were to investigate the influence of conceptual processing on (a) the age distribution, (b) phenomenological experience, and (c) the number of retrieved events in olfactory evoked autobiographical odor memory.

\section{Background}

Semantic knowledge has been demonstrated to influence olfactory processing in various tasks, such as hedonic evaluations, recognition, odor naming, and perceived familiarity (Larsson, 1997). Potential influences of semantic knowledge on the age distributions, phenomenological experience, and the number of evoked memories were investigated by varying three cue conditions: odor-only, name-only (i.e., the odors' names), and odor-name (odors in conjunction with their names). Previous work on odor-evoked events suggests that olfactory cues may elicit more emotional memories than other cue types (Herz \& Cupchik, 1995) although others have failed to replicate this observation (Ehrlichman \& Bastone, 1992; Willander \& Larsson, 2006). A possible explanation for these discrepant findings may be procedural differences between studies. For example, experiential qualities may have been assessed in conjunction with the olfactory stimulation or after the stimulus presentation. However, because passive smelling increases the activation of amygdala, olfactory perception may potentially influence the evaluation of retrieved events (Savic, Gulyas, Larsson, \& Roland, 2000). Thus, the emotional advantage may be a result of participants evaluating the odor cue rather than the retrieved memory. In order to address this issue two different rating conditions were included, where retrieved events were evaluated either with or without the retrieval cue. Thus, the main aims of Study II were to investigate whether (a) verbal and conceptual processing influence the age distribution and phenomenological qualities of olfactory evoked memories; and (b) whether experiential qualities of retrieved information are influenced by olfactory perception. An additional aim was to investigate vantage point (i.e., field, and observer) in autobiographical odor memory.

\section{Design}

The basic design of Study II was a 3 (Cue type: name-only, odor-only, odorname) x 2 (Rating condition: with cue, without cue) x 8 (Decade) mixed 
factorial design with cue type as between-group factor and rating condition and decade as within-group factors.

\section{Method}

Seventy-two healthy participants (50 women and 22 men; mean age 71.7 years; age range 65-80 years) were recruited from senior-citizen organizations in the Stockholm and Uppsala areas. The participants were randomized into one of three cue conditions (name-only, odor-only, or odor-name). The participants were presented with 20 cues and asked to relate any autobiographical event for a given cue. Thirty seconds were allowed for retrieval. Also, for half of the cues the retrieved memories were rated in conjunction with the cues and for the other half ratings were made without the cues. Retrieved memories were rated on perceived pleasantness, intensity, the feeling of being brought back in time, vividness, general emotionality, and vantage point. The memories were subsequently dated.

\section{Results}

As revealed by the analyses, Study II replicated the observations from Study I (see Figure 6), by showing that, the odor-only evoked memories peaked in the first decade of life (i.e., $\leq 10$ years). No reliable bump was observed for the name-only condition. Interestingly, for the odor-name condition the bump was located to the first and second decades of life. That is, the proportion of memories in the first ( $<10$ years) and second decade (11-20 years) did not differ reliably. With regard to phenomenological experience (see Figure 7), a main effect of cue type was observed for pleasantness, such that odorsonly produced stronger feelings of pleasantness than did the name-only condition. The memories evoked by odor-names did not differ from odor-only or name only on rated pleasantness. For general emotionality, odor-only evoked memories were associated with stronger emotionality than nameonly and odor-name evoked memories although the latter two did not differ. Regarding the feeling of being brought back in time, a main effect of cue type was observed, such that memories evoked in the odor-only condition produced stronger feelings of being brought back in time to the occurrence of the events than did the name-only or odor-name conditions. The latter two conditions did not differ. A main effect of rating condition was observed only for ratings of vividness, such that events rated in conjunction with the respective cues were experienced as more vivid compared to events rated without cues. No other comparisons were significant. Thus, the present findings suggest that the perceptual stimulation alone cannot account for the higher emotional arousal. Also, most memories were experienced in the field mode rather than observer or neither, although the observer mode was more common than neither. Finally, the odor-only condition evoked fewer memo- 
ries than did the name-only and odor-name conditions, whereas the latter two produced an equal amount of memories.

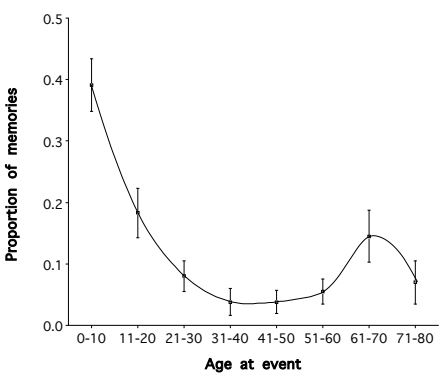

(a)

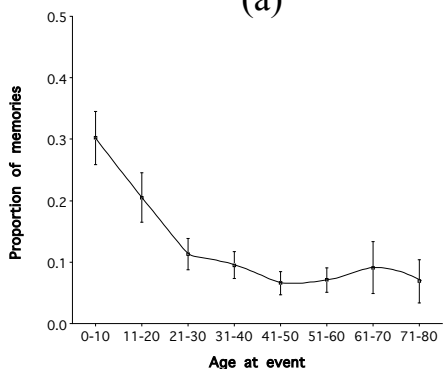

(c)

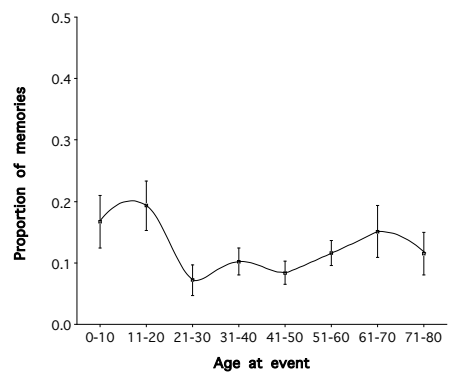

(b)

Figure 6. The distribution of (a) odor-only, (b) name-only, and (c) odor-name evoked autobiographical memories across the life-span. Error bars indicate \pm 1 standard error. 


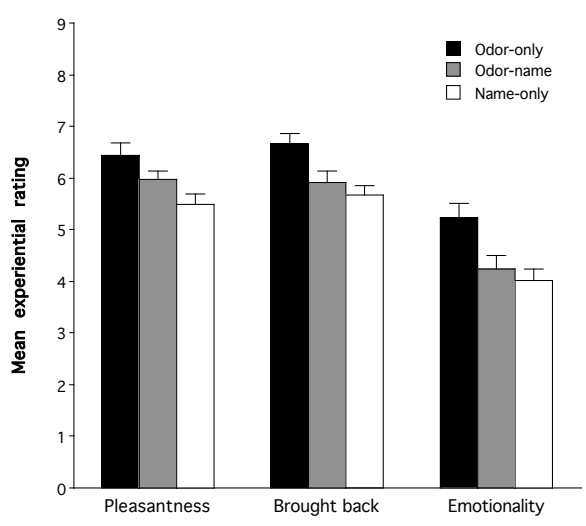

Figure 7. Experiential ratings across cue type. Error bars indicate \pm 1 standard error.

\section{Conclusion}

The overall pattern of findings suggest that retrieval of olfactory evoked information is sensitive to semantic and conceptual processing, and that odor-evoked representations are more emotional than memories triggered by verbal information. 


\section{Study III}

Willander, J., \& Larsson, M. (submitted). The mind's nose and autobiographical odor memory.

\section{Aim}

The aim of Study III was to investigate the influence of odor imagery on the retrieval of autobiographical memory information, and to examine potential relationships among imagery ability, memory, and phenomenological qualities.

\section{Background}

Several studies on olfactory imagery indicate that the evocation of an olfactory image mimics real olfactory perception. Support for olfactory imagery is available from a wide range of methodologies. For example, Djordjevic et al. (2004) demonstrated that olfactory imagery influences odor detection accuracy, such that evocation of olfactory images mismatched to the target odors decreases detection accuracy. Moreover, neuroimaging evidence suggests that brain regions involved in processing of olfactory information also are activated during odor imagery (Djordjevic, Zatorre, Petrides, Boyle, \& Jones-Gotman, 2005). To our knowledge, this is the first study on the potential influence of olfactory imagination on the retrieval of autobiographical information and phenomenological experiences.

\section{Design}

The basic design was a 2 (Cue type: word, odor imagery) x 8 (Decade) mixed factorial design where the first factor was a between-group factor and the second a within-group factor.

\section{Method}

Sixty-four healthy participants (41 women and 23 men; mean age 72.1; age range 64-80 years) residing in the Skelleftea and Stockholm areas were recruited. Participants were randomized into one of two conditions (i.e., odorimagery or word). The participants were presented with 20 word cues and 30 seconds were allowed for retrieval. In the odor-imagery condition, participants were asked to imagine the odors represented by the words. In instances of successful odor imagery, the participants were instructed to relate any event associated with the olfactory image. The instruction in the word condition was the same but no reference to olfaction or odor imagery was made. Retrieved memories were rated on valence, intensity, the feeling of being 
brought back in time, vividness, and general emotionality. Also participants were asked to indicate whether they had any sensory experience while recollecting the events. After all cues had been presented, the retrieved memories were dated.

\section{Results}

The main findings from Study III are shown in Figure 8. The results indicated that the bump of the odor imagery condition was located to the first decade of life ( $<10$ years), whereas the age distribution for the word-evoked events peaked in the second decade of life. The number of retrieved events was equal for both conditions. Memories evoked by odor imagery entailed more sensory experiences than events evoked by words. Specifically, the odor-imagery condition produced more visual and olfactory details in the retrieved events. Regarding phenomenological experience no differences between the two conditions were observed for any measure.

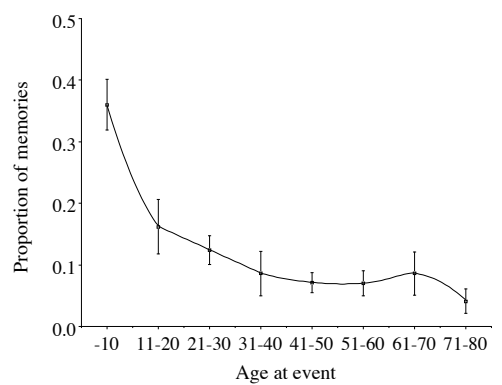

(a)

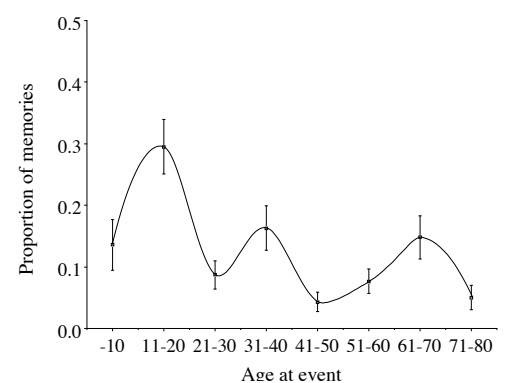

(b)

Figure 8. The distribution of (a) odor-imagery evoked, and (b) word-evoked memories across the life-span. Error bars indicate \pm 1 standard error.

\section{Conclusion}

The results from Study III suggest that olfactory imagery influences temporal but not experiential qualities of retrieved autobiographical memory information. 


\section{Discussion}

The main aims of the present thesis were to investigate autobiographical odor memory with regard to: (a) whole life-span age-distributions, (b) phenomenological experiences, (c) conceptual processing, and (d) olfactory imagery.

The main findings were that: (a) odors evoke older memories than verbal and visual information, (b) odors evoke more emotional events than verbal cues and produce a stronger feeling of being brought back in time to the occurrence of the event than words and pictures, (c) semantic knowledge of olfactory cues produces a shift from a perceptually driven to a more conceptually driven retrieval, and that (d) imagined odor cues mimic the age distribution of real olfactory cues.

Below, some of the obtained results will be highlighted and discussed. In particular, the discussion will highlight potential explanations for the location of the olfactory bump, the obtained differences in phenomenological experience, and the efficiency of odor cues to evoke autobiographical information.

\section{The age distribution of autobiographical odor memory}

The results of this thesis replicate and extend previous evidence by showing that memories triggered by olfactory information are localized to the first decade of life ( $<10$ years) rather than to young adulthood.

Specifically, Study I-III demonstrated that the bump location is not a fixed property of the age distribution of memories. Rather, the location of the bump varies as a function of the cue type. Considering this observation, it is of interest to discuss some potential explanations of the early location of the odor bump. Here, the following topics will be highlighted: (a) The role played by perceptual and conceptual processes (b) The contribution of selection strategies to the bump location, and (c) Ontogenetical development. 


\section{Perceptual and conceptual processing}

The results from Study I indicated that different cue types resulted in different locations of the bump. More specifically, odor-cued memories peaked in the first decade ( $<10$ years) of life, whereas word- and picture-cued events peaked in the second decade (11-20 years). However, olfactory perception often entails attempts to identify the odor and evidence indicates that semantic processes influence olfactory perception and memory (Larsson, 1997). Because Willander and Larsson (2006) did not control for olfactory semantic knowledge (i.e., odor identification) in Study I, this issue was further explored in Study II. To examine the potential role of perceptual and conceptual processes in the retrieval of autobiographical odor information, three retrieval conditions in Study II were formed: a perceptual (odor-only), a semantic (name-only), and a mixed condition (perceptual and semantic; odor-name). Study II demonstrated that when participants retrieved memories in the odor-only condition, the bump was located to the first decade of life, whereas the distribution showed a tendency to peak in the second decade for the name-only condition. In the odor-name condition the age distribution took an intermediate position between the name-only and odor-only conditions, with a bump localized to the first two decades of life $(0-20$ years). On the basis of these findings, we concluded that additional semantic knowledge of an odor produces a shift in processing from a more perceptually driven to a more conceptually driven retrieval. According to Paivio's (1991) dual code theory, odors are not stored in a dual code format (i.e., as a verbal and perceptual representation). The results of Study II support this notion because if olfactory knowledge would play a fundamental role in the generation of the bump, the odor-only condition would not differ from the odor-name or name-only conditions. Consequently, it may be suggested that autobiographical memories triggered by olfactory information primarily is driven by the perceptual properties of the specific odor.

Further support for a shift from a more perceptually to a more conceptually driven retrieval with available semantic knowledge was provided by the phenomenological ratings. Specifically, experiences of pleasantness, emotionality, and the feeling of being brought back in time, were lower when the odor was presented with the respective name as compared to when only an odor was presented. When participants were aware of the odor's identity the experiential ratings did not differ from the ratings obtained in the name-only condition. If odor cuing of events would have been semantically driven, the levels of phenomenological experience would not have been susceptible to this manipulation. 


\section{Retrieval modes and selection strategies}

Research suggests that different retrieval strategies may influence event selection and also the age distribution of autobiographical events (Conway \& Pleydell-Pearce, 2000). Two modes of retrieval have been suggested: generative or direct (Conway \& Pleydell-Pearce, 2000; Norman \& Bobrow, 1979). In generative retrieval, autobiographical information is validated in relation to an event description. In direct retrieval, a cue activates a pattern of highly associated autobiographical information, resulting in an immediate and effortless recollection. Thus, selection is bypassed in the direct retrieval mode (Conway \& Pleydell-Pearce, 2000). It has been suggested that highly perceptual cues (e.g., odors) more often result in a direct recollection (Conway \& Pleydell-Pearce, 2000) whereas verbal cues (e.g., words) activate generative search strategies. In Study II, the verbal and olfactory cues may have activated different retrieval strategies, such that retrieval in the odor cue condition may have been more driven by direct processes, whereas generative processes may have driven retrieval in the verbal condition. Thus, the present findings suggest that retrieval of autobiographical memory triggered by olfactory information may bypass the selection process resulting in an earlier bump location. However, when semantic information of odor cues is available, generative retrieval may become activated. As was demonstrated in Study II, additional semantic information regarding the odor cues resulted in a bump spanning both the olfactory and verbally activated bump region.

\section{Ontogenetical development}

Another aspect concerns the development of the sensory systems. Biological research suggests that our sensory systems undergo critical periods. A critical period may be defined as a period during which a sensory modality is highly susceptible to experience dependent learning (Browman, 1989; Knudsen, 2004). For a specific time frame, learning is more efficient and the number of encoded memories is greater during critical than non-critical periods. Although animal studies indicate that critical periods typically do not last long, it is possible that the higher chemosensory orientation observed in children optimize olfactory encoding that ultimately results in more distinct olfactory representations in childhood than later portions of life (Hvastja \& Zanuttini, 1989; Moriceau \& Sullivan, 2004). It is well established that olfaction plays a significant role early in life. For example, in order to increase the chances of survival, olfactory information pertaining to nutrition and kin recognition is encoded already in the prenatal period (Hepper \& Cleland, 1999; Porter, 1999; Schaal, Marlier, \& Soussignan, 1998, 2000; Weisfeld, Czilli, Phillips, Gall, \& Lichtman, 2003). Another factor of potential importance concerns how young children explore the environment. Most children often make investigations by placing things in the mouth or biting, resulting 
in chemosensory sensations and associations. If the frequency of olfactory memories or amount of olfactory information embedded in autobiographical events is higher in events from earlier than later parts of life the likelihood for retrieval of early memories will increase. Also, to consolidate new information encoded during periods of rapid changes and many novel cues, stable periods are needed (Rubin et al., 1998). In the case of olfaction, the stable period may potentially begin at approximately the age of 10 followed by at shift towards the relative greater importance of our primary sensory systems (e.g., vision, hearing). A potential account of the odor bump may therefore be an increased olfactory orientation in childhood (i.e., $<10$ years) followed by a decrease of new odor associations in adulthood; as a result associations are more stable in childhood than adulthood.

\section{Phenomenological experience}

The objectives across Study I-III with regard to phenomenological experiences in autobiographical odor memory were to elucidate: (a) potential differences in phenomenological experience across cue types, (b) perceptual and conceptual influences on experiential factors, and (c) influences of olfactory imagery on the re-experience of events.

\section{Emotionality}

As noted above, Study I did not replicate previous findings of an olfactory advantage in retrieval of emotional autobiographical memories (Herz, 2004; Herz \& Cupchik, 1995; Herz \& Schooler, 2002). Rather, in Study I pictureevoked were experienced as more emotional compared to odor- and verbally evoked events. Interestingly, similar results were reported by Ehrlichman and Bastone (1992), who demonstrated a pictorial advantage in the retrieval of emotional events. In addition, no significant differences across cue types were observed when measuring the pleasantness, intensity, or general emotionality at recollection. Also, no difference in emotionality was found across the life-span suggesting that emotionality was unrelated to the bump. In contrast, the results from Study II revealed that memories evoked by odors were more emotional than memories evoked by words.

Also, the retrieved events were rated following one of two rating conditions, with or without the cues. The results in Study II indicated no effect of rating condition, but a main effect of cue type, suggesting that odor-evoked memories indeed were more emotional than events evoked by words. A potential explanation for the discrepant findings in emotionality between Study I and II may be methodological differences. In Study I, the experimental protocol comprised more experiential dimensions compared to Study II, which may have influenced the emotional evaluations, such that the greater number of 
evaluations may potentially have separated the participants from their phenomenological experiences associated with the events.

Thus in the light of previous work (e.g., Chu \& Downes, 2002; Herz, 2004; Herz \& Cupchik, 1995; Herz \& Schooler, 2002) it is suggested that autobiographical odor memories are more emotional per se and that reinstatement of retrieval cues do not influence the evaluation of the retrieved events. Thus, the emotional advantage of odors is primarily driven by the sensory system's influence on the retrieval or selection process.

\section{Brought back in time}

In line with previous work, Study I and II demonstrated that odor-evoked memories produced stronger feelings of being brought back in time to the occurrence of the event than words and pictures (Herz, 2004; Herz \& Schooler, 2002). The underlying mechanisms for the stronger feeling of being brought back in time are unclear. A potential explanation for the stronger feeling of being brought back when recollecting autobiographical odor memories may be the direct synapsing between the olfactory bulb and the hippocampus. The hippocampus is involved in the temporal processing of information and is critical for the retrieval of episodic information (Ergorul \& Eichenbaum, 2004; Herz \& Engen, 1996). Another critical brain region for the recollection of autobiographical information is the prefrontal cortex (Cabeza et al., 1997; Habib, Nyberg, \& Tulving, 2003; Tulving, 2002; Wheeler, Stuss, \& Tulving, 1997). Thus, odor cues may potentially activate the hippocampus and prefrontal regions during autobiographical memory retrieval producing a stronger temporal autonoetic awareness.

\section{Olfactory imagery and phenomenological experiences}

Research indicates that odor imagery activates regions similar to odor perception (Djordjevic et al., 2005). Study III aimed at investigating influences of odor imagery on the phenomenological experience of autobiographical memories. No differences were observed between odor imagery- and wordcued events for pleasantness, intensity, the feeling of being brought back in time, vividness, or general emotionality. Although odors are difficult to imagine, the participants were successful in the evocation of olfactory images. Participants also retrieved memories with an age distribution resembling that of odor-evoked events. These findings indicate that the lack of difference between the imagery and word condition was genuine and not due to experimental limitations. However, considering the amount of evoked sensory information in the retrieved memories odor, imagery was more efficient than word cues in eliciting information. A potential source for this phenomenological discrepancy may be that reflective qualities (e.g., emotionality, the feeling of being brought back in time) and perceptual qualities (e.g., 
visual, olfactory sensation) are supported by different brain regions (Larsen, 1998). Taken together, the results from Study III suggest that odor imagery cues are not sufficient for eliciting stronger phenomenological experiences in autobiographical memories.

\section{Efficiency of odor cues to evoke memories}

The efficiency of different cue types to evoke autobiographical events was measured by the number of evoked memories. In line with previous research, the odor conditions of Study I did not evoke more memories than word-cues. In Study II the odor-only condition evoked less memories than did the nameonly or odor-name condition. One potential explanation for this observation is cue specificity. It has been suggested that odors are more specific cues than verbal or pictorial information. Odors may therefore match fewer memories than more generic cues such as words or pictures.

\section{General considerations}

\section{Single versus double-cuing}

Study I-III employed the Galton-Crovitz method with a single cueing procedure. Previous work on autobiographical odor memory has used both single and double-cuing methods (see e.g., Chu \& Downes, 2002; Herz \& Schooler, 2002). In the double-cuing method participants are re-exposed to an additional cue and asked to relate any new information. The double-cuing method enables comparisons of information evoked by different cue types controlling for the selection of events (Chu \& Downes, 2002; Herz \& Schooler, 2002). According to Herz and Schooler (2002), the double cuing method offers some advantages over single cuing procedures such as control over memory selection. However, two points of caution are warranted: first, perceptual influences in the selection phase are not investigated in the double-cuing procedure. Second, the double cuing procedure is complicated for the participants. Also, at a psychological level, it is difficult to assess information retrieved in the additional cuing phase in relation to the selectionretrieval phase. Given these limitations, the single-cuing procedure was chosen across Study I-III.

\section{Veridicality of retrieved events}

One of the limitations of the Galton-Crovitz method is the lack of control regarding the veridicality of the retrieved memories (Rubin, 2005b). Although some of the retrieved information may have been inaccurate or 
falsely generated in Study I-III it is highly unlikely that these errors produced a reliable influence on the phenomenological experiences or age distributions. However, a critical issue concerns whether the amount of false information varies across cue types, such that olfactory cues would be more susceptible in evoking less accurate memories. However, to the best of my knowledge, there is no available evidence suggesting a variation in the amount of inaccurate or false information over different sensory cues. The generation of false information as a function of different cue types is a topic that needs to be addressed in future research.

\section{Matching of cues across modalities}

The main selection of olfactory cues for Study I-III was based on the items selected by Rubin et al. (1984) and Chu and Downes (2000). In addition, the following criteria had to be fulfilled to allow inclusion: (a) cue items had to be presentable as words, pictures and odors, (b) cues were not allowed to represent specific periods of life, (c) because the aims were to investigate specific events, highly familiar olfactory information (e.g., coffee) was avoided in order to prevent retrieval of general events, (d) highly trigeminal cues were excluded, and (f) no hazardous odors were included (e.g., gas).

The cues used in Study I-III were evaluated in a pilot study and matched with regard to specificity. As a result, all cues were presented in a highly prototypic form. Further, the visual cues were photographed in front of a white background and the olfactory stimuli were based all on natural odor sources. Thus, the obtained differences in phenomenological experience and age distribution of the retrieved events should not have been due to systematic differences in the presentation the cues.

\section{Suggestions for future studies}

Scientific evidence concerning autobiographical odor memory is limited in comparison to knowledge regarding verbal cuing of events. Four different topics for future studies are suggested: (1) neuroimaging studies, (2) individual differences, (3) multimodal cues, and (4) false memory.

Neural correlates of autobiographical odor memory. Autobiographical memory has been addressed in a number of neuroimaging studies (see Svoboda, McKinnon, \& Levine, 2006). However, few studies have addressed the neural basis for autobiographical odor memory (see Herz, Eliassen, Beland, \& Souza, 2004). Brain activation studies may elucidate brain processes involved in the retrieval of events across different cue formats. Of specific interest are studies aimed at understanding the role of amygdala and hippocampus regarding emotional and temporal aspects of autobiographical 
events. The temporal distribution of autobiographical odor memories may also be elucidated by investigating brain regions involved it the retrieval of autobiographical memories. The olfactory bulb synapses directly to the limbic system with close connection to both the amygdala and the hippocampus. Interestingly, the hippocampus has been suggested to play an a key role in the temporal organization of memory (Ergorul \& Eichenbaum, 2004).

Individual differences. Statistical analyses on the age distribution of autobiographical memory are based on group data (i.e., group mean value). However, individual differences may be observed with regard to phenomenological experience and age distributions of retrieved autobiographical events. Studies on autobiographical memory based on person-oriented methods, are not available (see Lövdén, Bergman, Adolfsson, Lindenberger, \& Nilsson, 2005). For example, it would be highly interesting to investigate the relative impact of certain profiles (e.g., personality profiles, olfactory profiles, memory performance profiles) on phenomenological experience and age distributions.

Multimodal cuing. Most studies on autobiographical memory have used unimodal cues. However, as was demonstrated in Study II, presentation of two retrieval cues resulted in a different outcome than did a single-cue presentation (i.e., unimodal retrieval). Since the environment is multimodal it would be of interest to investigate multimodal cuing of memories to increase the ecological validity and to evaluate a potential impact of multi-modal cuing on age distributions and phenomenological experiences.

\section{Concluding remarks}

The present to investigated autobiographical odor memory with regard to age distribution and phenomenological experience. The results indicated that memories evoked by olfactory information are older than memories evoked by verbal and visual information. The results from Study II indicated that odor memories were more emotional than verbally evoked ones. Also, the present work showed that odor-evoked information is associated with stronger feelings of being brought back in time. Further, odors were not more efficient (i.e., number of evoked memories) reminders of past experiences. Finally, imagined odor cues mimic olfactory retrieval of autobiographical events with regard to temporal aspects (i.e., the bump was located in the first decade of life) but not for phenomenological experiences. Overall, this pattern of findings suggests that memories triggered by the olfactory sensory system are different from memories triggered by verbal or visual information. 


\section{References}

Aggleton, J. P., \& Waskett, L. (1999). The ability of odours to serve as statedependent cues for real-world memories: can Viking smells aid the recall of Viking experiences? British Journal of Psychology, 90(1), $1-7$.

Anderson, S. J., \& Conway, M. A. (1993). Investigating the structure of autobiographical memories. Journal of Experimental Psychology: Learning, Memory, and Cognition, 19(5), 1178-1196.

Arshamiam, A., Willander, J., \& Larsson, M. (2007). Olfactory Dreams, Interest, and Imagery: Relationships to Olfactory Memory.

Ashton, R., \& White, K. D. (1980). Sex differences in imagery vividness: An artifact of the test. British Journal of Psychology, 71(1), 35-38.

Baddeley, A. (1994). Working memory: The interface between memory and cognition. In D. L. Schacter \& E. Tulving (Eds.), Memory systems 1994 (pp. 351-367). Cambridge, Massachusettes: The MIT Press.

Baddeley, A. (2000). The episodic buffer: a new component of working memory? Trends in Cognitive Science, 4(11), 417-423.

Baddeley, A. (2003). Working memory: looking back and looking forward. Nature Reviews Neuroscience, 4(10), 829-839.

Banaji, M. R., \& Crowder, R. G. (1989). The bankruptcy of everyday memory. American Psychologist, 44(9), 1185-1193.

Barclay, C. R. (1999). Autobiographical remembering: Narrative constraints on objectified selves. In D. C. Rubin (Ed.), Remembering our past (pp. 94-125). Cambridge: Cambridge University Press.

Bensafi, M., Porter, J., Pouliot, S., Mainland, J., Johnson, B., Zelano, C., et al. (2003). Olfactomotor activity during imagery mimics that during perception. Nature Neuroscience, 6(11), 1142-1144.

Bensafi, M., \& Rouby, C. (2007). Individual differences in odor imaging ability reflect differences in olfactory and emotional perception. Chemical Senses, 32(3), 237-244.

Berntsen, D. (2002). Tunnel memories for autobiographical events: central details are remembered more frequently from shocking than from happy experiences. Memory \& Cognition, 30(7), 1010-1020.

Berntsen, D., \& Hall, N. M. (2004). The episodic nature of involuntary autobiographical memories. Memory \& Cognition, 32(5), 789-803.

Berntsen, D., \& Rubin, D. C. (2002). Emotionally charged autobiographical memories across the life span: The recall of happy, sad, traumatic and involuntary memories. Psychology and Aging, 17(4), 636-652. 
Berntsen, D., \& Rubin, D. C. (2004). Cultural life scripts structure recall from autobiographical memory. Memory \& Cognition, 32(3), 427442.

Berntsen, D., \& Rubin, D. C. (2006). Emotion and vantage point in autobiographical memory. Cognition \& Emotion, 20(8), 1193-1215.

Bower, G. B. (2000). A brief history of memory research. In E. Tulving \& F. I. M. Craik (Eds.), The Oxford handbood of memory (pp. 3-32). Oxford: Oxford University Press.

Browman, H. I. (1989). Embryology, ethology and ecology of ontogenetic critical periods in fish. Bran Behav Evol., 34(1), 5-12.

Bruce, D. (1991). Mechanistic and functional explanations of memory. American Psychologist, 46(1), 46-48.

Bruce, D., Wilcox-O'Hearn, L. A., Robinson, J. A., Phillips-Grant, K., Francis, L., \& Smith, M. (2005). Fragment memories mark the end of childhood amnesia. Memory \& Cognition, 33(4), 567-576.

Cabeza, R., Mangels, J., Nyberg, L., Habib, R., Houle, S., McIntosh, A. R., et al. (1997). Brain regions differentially involved in remembering what and when: a PET study. Neuron, 19(4), 863-870.

Cabeza, R., \& St Jacques, P. (2007). Functional neuroimaging of autobiograpical memory. Trends in Cognitive Science, 11(5), 219-227.

Cahill, L., Babinsky, R., Markowitsch, H. J., \& McGaugh, J. L. (1995). The amygdala and emotional memory. Nature, 377(6547), 295-296.

Cahill, L., Haier, R. J., Fallon, J., Alkire, M. T., Tang, C., Keator, D., et al. (1996). Amygdala activity at encoding correlated with long-term, free recall of emotional information. Proceedings of the National Academy of Sciences USA, 93(15), 8016-8021.

Canli, T., Zhao, Z., Brewer, J., Gabrieli, J. D., \& Cahill, L. (2000). Eventrelated activation in the human amygdala associates with later memory for individual emotional experience. Journal of Neuroscience, 20(19), RC99.

Cann, A., \& Ross, D. A. (1989). Olfactory stimuli as context cues in human memory. American Journal of Psychology, 102(1), 91-102.

Carrasco, M., \& Ridout, J. B. (1993). Olfactory perception and olfactory imagery: A multidimensional analysis. Journal of Experimental Psychology: Human Perception and Performance, 19(2), 287-301.

Ceci, S. J., \& Bronfenbrenner, U. (1991). On the demise of everyday memory: "The rumors of my death are much exaggerated" (Mark Twain). American Psychologist, 46(1), 27-31.

Chu, S., \& Downes, J. J. (2000). Long live Proust: The odour-cued autobiographical memory bump. Cognition, 75(2), B41-B50.

Chu, S., \& Downes, J. J. (2002). Proust nose best: Odors are better cues of autobiographical memory. Memory \& Cognition, 30(4), 511-518.

Conway, M. A. (1991). In defense of everyday memory. American Psychologist, 46(1), 19-26.

Conway, M. A., \& Haque, S. (1999). Overshadowing the reminiscence bump: Memories of a struggle for independence. Journal of Adult 
Development. Special Issue: Aging and autobiographical memory, $6(1), 35-44$.

Conway, M. A., \& Pleydell-Pearce, C. W. (2000). The construction of autobiographical memories in the self-memory system. Psychological Review, 107(2), 261-288.

Conway, M. A., Wang, Q., Hanyu, K., \& Haque, S. (2005). A Cross-Cultural Investigation of Autobiographical Memory: On the Universality and Cultural Variation of the Reminiscence Bump. Journal of CrossCultural Psychology, 36(6), 739-749.

Crovitz, H. F., \& Schiffman, H. (1974). Frequency of episodic memories as a function of their age. Bulletin of the Psychonomic Society(4), 517518.

D'Argembeau, A., Comblain, C., \& Van der Linden, M. (2003). Phenomenal characteristics of autobiographical memories for positive, negative, and neutral events. Applied Cognitive Psychology, 17(3), 281-294.

D'Argembeau, A., \& Van der Linden, M. (2004). Phenomenal characteristics associated with projecting oneself back into the past and forward into the future: Influence of valence and temporal distance. Consciousness and Cognition: An International Journal, 13(4), 844-858.

D'Argembeau, A., \& Van der Linden, M. (2006). Individual differences in the phenomenology of mental time travel: The effect of vivid visual imagery and emotion regulation strategies. Consciousness and Cognition, 15(2), 342-350.

Distel, H., \& Hudson, R. (2001). Odor judgements are influenced by subjects' knowledge of the odor source. Chemical Senses, 26(3), 247251.

Djordjevic, J., Zatorre, R. J., Petrides, M., Boyle, J. A., \& Jones-Gotman, M. (2005). Functional neuroimaging of odor imagery. Neuroimage, 24(3), 791-801.

Djordjevic, J., Zatorre, R. J., Petrides, M., \& Jones-Gotman, M. (2004). The Mind's Nose Effects of Odor and Visual Imagery on Odor Detection. Psychological Science, 15(3), 143-148.

Ebbinghaus, H. (1913). Memory: A contribution to experimental psychology. New York: Teachers College, Columbia University.

Ehrlichman, H., \& Bastone, L. (1992). Olfaction and emotion. In M. Serby $\&$ L. Chobor (Eds.), Science of olfaction (pp. 410-438). New York: Springer Verlag.

Elnick, A. B., Margrett, J. A., Fitzgerald, J. M., \& Labouvie-Vief, G. (1999). Benchmark memories in adulthood: Central domains and predictors of their frequency. Journal of Adult Development. Special Issue: Aging and autobiographical memory, 6(1), 45-59.

Engen, T., \& Ross, B. M. (1973). Long-term memory of odors with and without verbal descriptions. Journal of Experimental Psychology, 100(2), 221-227.

Ergorul, C., \& Eichenbaum, H. (2004). The hippocampus and memory for "what," "where," and "when". Learning \& Memory, 11(4), 397-405. 
Fitzgerald, J. M. (1988). Vivid memories and the reminiscence phenomenon: The role of a self narrative. Human Development, 31(5), 261-273.

Fivush, R., Haden, C., \& Adam, S. (1995). Structure and coherence of preschoolers' personal narratives over time: Implications for childhood amnesia. Journal of Experimental Child Psychology, 60(1), 32-56.

Fivush, R., \& Nelson, K. (2004). Culture and language in the emergence of autobiographical memory. Psychological Science, 15(9), 573-577.

Fromholt, P., \& Larsen, S. F. (1991). Autobiographical memory in normal aging and primary degenerative dementia (dementia of Alzheimer type). Journals of Gerontology, 46(3), P85-P91.

Fromholt, P., Mortensen, D. B., Torpdahl, P., Bender, L., Larsen, P., \& Rubin, D. C. (2003). Life-narrative and word-cued autobiographical memories in centenarians: Comparisons with 80-year-old control, depressed, and dementia groups. Memory, 11(1), 81-88.

Georgia, N., \& Neisser, U. (1983). Point of view in personal memories. Cognitive Psychology(15), 467-482.

Gilbert, A. N., Crouch, M., \& Kemp, S. E. (1998). Olfactory and visual mental imagery. Journal of Mental Imagery, 22(3-4), 137-146.

Gilboa, A. (2004). Autobiographical and episodic memory - one and the same? Evidence from prefrontal activation in neuroimaging studies. Neuropsychologia, 42(10), 1336-1349.

Goddard, L., Pring, L., \& Felmingham, N. (2005). The effects of cue modality on the quality of personal memories retrieved. Memory, 13(1), 79-86.

Goldman, W. P., \& Seamon, J. G. (1992). Very long-term memory for odors: retention of odor-name associations. American Journal of Psychology, 105(4), 549-563.

Graf, P., \& Schacter, D. L. (1985). Implicit and explicit memory for new associations in normal and amnesic subjects. Journal of Experimental Psychology: Learning, Memory, and Cognition, 11(3), 501-518.

Gupta, P., \& Cohen, N. J. (2002). Theoretical and computational analysis of skill learning, repetition priming, and procedural memory. Psychological Review, 109(2), 401-448.

Habib, R., Nyberg, L., \& Tulving, E. (2003). Hemispheric asymmetries of memory: the HERA model revisited. Trends in Cogntive Science, $7(6), 241-245$.

Halpern, A. R., \& Zatorre, R. J. (1999). When that tune runs through your head: a PET investigation of auditory imagery for familiar melodies. Cerebral Cortex, 9(7), 697-704.

Hausser-Hauw, C., \& Bancaud, J. (1987). Gustatory hallucinations in epileptic seizures. Electrophysiological, clinical and anatomical correlates. Brain, 110(2), 339-359.

Hepper, P. G., \& Cleland, J. (1999). Developmental aspects of kin recognition. Genetica, 104(3), 199-205.

Herz, R. S. (1997a). Emotion experienced during encoding enhances odor retrieval cue effectiveness. American Journal of Psychology, 110(4), 489-505. 
Herz, R. S. (1997b). The effects of cue distinctiveness on odor-based context-dependent memory. Memory \& Cognition, 25(3), 375-380.

Herz, R. S. (2000). Verbal coding in olfactory versus nonolfactory cognition. Memory \& Cognition, 28(6), 957-964.

Herz, R. S. (2003). The effect of verbal context on olfactory perception. Journal of Experimental Psychology: General, 132(4), 595-606.

Herz, R. S. (2004). A Naturalistic Analysis of Autobiographical Memories Triggered by Olfactory Visual and Auditory Stimuli. Chemical Senses, 29(3), 217-224.

Herz, R. S., \& Cupchik, G. C. (1995). The emotional distinctiveness of odorevoked memories. Chemical Senses, 20(5), 517-528.

Herz, R. S., Eliassen, J., Beland, S., \& Souza, T. (2004). Neuroimaging evidence for the emotional potency of odor-evoked memory. Neuropsychologia, 42(3), 371-378.

Herz, R. S., \& Engen, T. (1996). Odor memory: Review and analysis. Psychonomic Bulletin \& Review, 3(3), 300-313.

Herz, R. S., \& Schooler, J. W. (2002). A naturalistic study of autobiographical memories evoked by olfactory and visual cues: Testing the Proustian hypothesis. American Journal of Psychology, 115(1), 2132.

Herz, R. S., \& von Clef, J. (2001). The influence of verbal labeling on the perception of odors: Evidence for olfactory illusions? Perception, 30(3), 381-391.

Holmes, A., \& Conway, M. A. (1999). Generation identity and the reminiscence bump: Memory for public and private events. Journal of Adult Development. Special Issue: Aging and autobiographical memory, 6(1), 21-34.

Howe, M. L., \& Courage, M. L. (1997). The emergence and early development of autobiographical memory. Psychological Review, 104(3), 499-523.

Hvastja, L., \& Zanuttini, L. (1989). Odour memory and odour hedonics in children. Perception, 18(3), 391-396.

Hyland, D. T., \& Ackerman, A. M. (1988). Reminiscence and autobiographical memory in the study of the personal past. Journals of Gerontology, 43(2), 35-P39.

Jansari, A., \& Parkin, A. J. (1996). Things that go bump in your life: Explaining the reminiscence bump in autobiographical memory. Psychology and Aging, 11(1), 85-91.

Janssen, S. M. J., Chessa, A. G., \& Murre, J. M. J. (2005). The reminiscence bump in autobiographical memory: Effects of age, gender, education, and culture. Memory, 13(6), 658-668.

Kaski, D. (2002). Revision: Is visual perception a requisite for visual imagery? Perception, 31(6), 717-731.

Knudsen, E. I. (2004). Sensitive periods in the development of the brain and behavior. Journal of Cognitive Neuroscience, 16(8), 1412-1425. 
Kormi-Nouri, R. (2000). The role of movement and object in action memory: a comparative study between blind, blindfolded and sighted subjects. Scandinavian Journal of Psychology, 41(1), 71-75.

Kormi-Nouri, R., Nyberg, L., \& Nilsson, L. G. (1994). The effect of retrieval enactment on recall of subject-performed tasks and verbal tasks. Memory \& Cognition, 22(6), 723-728.

Kosslyn, S. M., Ganis, G., \& Thompson, W. L. (2001). Neural foundations of imagery. Nature Reviews Neuroscience, 2(9), 635-642.

Lang, P. J., Bradley, M. M., \& Cuthbert, B. N. (1999). International affective picture system (IAPS): technical manual and affective ratings. Gainesville, FL: Center for Research in Psychophysiology, University of Florida.

Larsen, S. F. (1998). What is it like to remember? On phenomenological qualities of memory. In C. P. Thompson, D. J. Hermann, D. Bruce, J. D. Reed, D. G. Payne \& M. P. Toglia (Eds.), Autobiographical memory: Theoretical and applied perspectives (pp. 163-190). Mahwah, New Jersey: Lawrence Earlbaum Associates.

Larsen, S. F., Schrauf, R. W., Fromholt, P., \& Rubin, D. C. (2002). Inner speech and bilingual autobiographical memory: A Polish-Danish cross-cultural study. Memory, 10(1), 45-54.

Larsson, M. (1997). Semantic factors in episodic recognition of common odors in early and late adulthood: a review. Chemical Senses, 22(6), 623-633.

Larsson, M. (2002). Odor memory: A memory systems approach. In C. Rouby, B. Schaal, D. Dubois, D. Gervais \& A. Holley (Eds.), Olfaction, taste, and cognition (pp. 231-245). Cambridge: Cambridge University Press.

Larsson, M., \& Bäckman, L. (1993). Semantic activation and episodic odor recognition in young and older adults. Psychology and Aging, 8(4), $582-588$.

Larsson, M., \& Bäckman, L. (1997). Age-related differences in episodic odour recognition: The role of access to specific odour names. Memory, 5(3).

Larsson, M., \& Melinder, A. (2007). Underestimated sensations: Everyday odour memory in clinical and forensic settings. In S. Magnusson \& T. Helstrup (Eds.), Everyday memory (pp. 91-107): Psychology Press.

Lawless, H. T. (1978). Recognition of common odors, pictures, and simple shapes. Perception \& Psychophysics, 24(6), 493-495.

Loftus, E. F. (1991). The glitter of everyday memory... and the gold. American Psychologist, 46(1), 16-18.

Lövdén, M., Bergman, L., Adolfsson, R., Lindenberger, U., \& Nilsson, L. G. (2005). Studying individual aging in an interindividual context: typical paths of age-related, dementia-related, and mortality-related cognitive development in old age. Psychology and Aging, 20(2), 303316. 
Mackavey, W. R., Malley, J. E., \& Stewart, A. J. (1991). Remembering autobiographically consequential experiences: Content analysis of psychologists' accounts of their lives. Psychology and Aging, 6(1), 50-59.

Marklund, P., Fransson, P., Cabeza, R., Petterson, K. M., Ingvar, M., \& Nyberg, L. (2007). Sustained and transient neural modulations in prefrontal cortex related to declarative long-term memory, working memory, and attention. Cortex, 43(1), 22-37.

Markowitsch, H. J., Vandekerckhove, M. M., Lanfermann, H., \& Russ, M. O. (2003). Engagement of lateral and medial prefrontal areas in the ecphory of sad and happy autobiographical memories. Cortex, 39(45), 643-665.

Marks, D. F. (1973). Visual imagery differences in recall of pictures. British Journal of Psychology, 64(1), 17-24.

McIsaak, H., \& Eich, E. (2002). Vantage point in episodic memory. Psychonomic Bulletin \& Review, 9(1), 146-150.

McIsaak, H., \& Eich, E. (2004). Vantage point in traumatic memory. Psychological Science, 15(4), 248-253.

Moriceau, S., \& Sullivan, R. M. (2004). Unique neural circuitry for neonatal olfactory learning. Journal of Neuroscience, 24(5), 1182-1189.

Nelson, K., \& Fivush, R. (2004). The Emergence of Autobiographical Memory: A Social Cultural Developmental Theory. Psychological Review, 111(2), 486-511.

Newcombe, N. S., Drummey, A. B., Fox, N. S., Lie, E., \& Ottinger-Alberts, W. (2000). Remembering early childhood: How much, how, and why (or why not). Current Directions in Psychological Science, $9(2), 55-58$.

Norman, D. A., \& Bobrow, D. G. (1979). Descriptions and intermediate stage in memory retrieval. Cognitive Psychology, 11, 107-123.

Nyberg, L., \& Nilsson, L. G. (1995). The role of enactment in implicit and explicit memory. Psychological Research, 57(3-4), 215-219.

Nyberg, L., Petersson, K. M., Nilsson, L. G., Sandblom, J., Åberg, C., \& Ingvar, M. (2001). Reactivation of motor brain areas during explicit memory for actions. Neuroimage, 14(2), 521-528.

Olsson, M. J., \& Fridén, M. (2001). Evidence of odor priming: edibility judgements are primed differently between the hemispheres. Chemical Senses, 26(2), 117-123.

Paivio, A. (1991). Dual coding theory: Retrospect and current status. Canadian Journal of Psychology, 45(3), 255-287.

Perkins, J., \& McLaughlin Cook, N. (1990). Recognition and recall of odours: The effects of suppressing visual and verbal encoding processes. British Journal of Psychology, 81, 221-226.

Phelps, E. (2004). Human emotion and memory: Interactions of the amygdala and hippocampal complex. Current Opinion in Neurobiology, 14(2), 198-202.

Pointer, S. C., \& Bond, N. W. (1998). Context-dependent memory: Colour versus odor. Chemical Senses, 23(3), 359-362. 
Porter, R. H. (1999). Olfaction and human kin recognition. Genetica, 104(3), 259-263.

Prince, S. E., Tsukiura, T., \& Cabeza, R. (2007). Distinguishing the Neural Correlates of Episodic Memory Encoding and Semantic Memory Retrieval. Psychological Science, 18(2), 144-151.

Proust, M. (1919). Du coté de chez Swann. Paris, France: Gallimard.

Ranaganath, C., Johnson, M. K., \& D'Esposito, M. (2003). Prefrontal activity associated with working memory and episodic long-term memory. Neuropsychologia, 41(3), 378-389.

Ritchie, T. D., Skowronski, J. J., Wood, S. E., Walker, W. R., Vogl, R. J., \& Gibbons, J. A. (2006). Event Self-importance, Event Rehearsal, and the Fading Affect Bias in Autobiographical Memory. Self and Identity, 5(2), 172-195.

Robinson, J. A., \& Swanson, S. (1993). Field and observer modes of remembering. Memory, 1(3), 169-184.

Robinson, J. A., \& Taylor, L. R. (1998). Autobiographical memory and selfnarratives: A tale of two stories. In C. P. Thompson, D. J. Hermann, D. Bruce, J. D. Reed, D. G. Payne \& M. P. Toglia (Eds.), Autobiographical memory: Theoretical and applied perspectives. Mahwah, New Jersey: Lawrence Earlbaum Associates.

Roediger, H. L. (1990). Implicit memory. Retention without remembering. American Psychologist, 45(9), 1043-1056.

Roland, P., \& Gulyás, B. (1994). Visual imagery and visual representation. Trends in Neurosciences, 17(7), 281-287.

Roland, P., \& Gulyás, B. (1995). Visual memory, visual imagery, and visual recognition of large field patterns by the human brain: functional anatomy by positron emission tomography. Cerebral Cortex, 5(1), 79-93.

Rubin, D. C. (1982). On the retention function for autobiographical memory. Journal of Verbal Learning \& Verbal Behavior, 21(1), 21-38.

Rubin, D. C. (2005a). A Basic-Systems Approach to Autobiographical Memory. Current Directions in Psychological Science, 14(2), 79-83.

Rubin, D. C. (2005b). Autobiographical Memory Tasks in Cognitive Research. In A. Wenzel \& D. C. Rubin (Eds.), Cognitive methods and their application to clinical research (pp. 219-241). Washington, DC: American Psychological Association.

Rubin, D. C. (2006). The basic-systems model of episodic memory. Psychological Science, 1(4), 277-311.

Rubin, D. C., \& Berntsen, D. (2003). Life scripts help to maintain autobiographical memories of highly positive, but not highly negative, events. Memory \& Cognition, 31(1), 1-14.

Rubin, D. C., Groth, E., \& Goldsmith, D. J. (1984). Olfactory cuing of autobiographical memory. Am J Psychol, 97(4), 493-507.

Rubin, D. C., Rahhal, T. A., \& Poon, L. W. (1998). Things learned in early adulthood are remembered best. Memory \& Cognition, 26(1), 3-19. 
Rubin, D. C., \& Schulkind, M. D. (1997a). Distribution of important and word-cued autobiographical memories in 20-, 35-, and 70-year-old adults. Psychology and Aging, 12(3), 524-535.

Rubin, D. C., \& Schulkind, M. D. (1997b). The distribution of autobiographical memories across the lifespan. Memory \& Cognition, 25(6), 859-866.

Rubin, D. C., Schulkind, M. D., \& Rahhal, T. A. (1999). A study of gender differences in autobiographical memory: Broken down by age and sex. Journal of Adult Development. Special Issue: Aging and autobiographical memory, 6(1), 61-71.

Rubin, D. C., \& Wenzel, A. E. (1996). One hundred years of forgetting: A quantitative description of retention. Psychological Review, 103(4), 734-760.

Rubin, D. C., Wetzler, S. E., \& Nebes, R. D. (1986). Autobiographical memory across the lifespan. In D. C. Rubin (Ed.), Remembering our past. Cambridge: Cambridge University Press.

Rugg, M. D., Fletcher, P. C., Chua, P. M., \& Dolan, R. J. (1999). The role of the prefrontal cortex in recognition memory and memory for source: an fMRI study. Neuroimage, 10(5), 520-529.

Savic, I., Gulyas, B., Larsson, M., \& Roland, P. (2000). Olfactory functions are mediated by parallel and hierarchical processing. Neuron, 26(3), 735-745.

Schaal, B., Marlier, L., \& Soussignan, R. (1998). Olfactory function in the human fetus: evidence from selective neonatal responsiveness to the odor of amniotic fluid. Behavioral Neuroscience, 112(6), 14381439.

Schaal, B., Marlier, L., \& Soussignan, R. (2000). Human foetuses learn odours from their pregnant mother's diet. Chemical Senses, 25(6), 729-737.

Schab, F. R. (1990). Odors and the remembrance of things past. Journal of Experimental Psychology: Learning, Memory, and Cognition, 16(4), 648-655.

Schacter, D. L., \& Tulving, E. (1994). What are the memory systems fo 1994? In D. L. Schacter \& E. Tulving (Eds.), Memory systems 1994 (pp. 1-38). Cambridge, Massachusetts: The MIT Press.

Schooler, J. W., \& Engstler-Schooler, T. Y. (1990). Verbal overshadowing of visual memories: Some things are better left unsaid. Cognitive Psychology, 22(1), 36-71.

Schrauf, R. W., \& Rubin, D. C. (1998). Bilingual autobiographical memory in older adult immigrants: A test of cognitive explanations of the reminiscence bump and the linguistic encoding of memories. Journal of Memory and Language, 39(3), 437-457.

Schrauf, R. W., \& Rubin, D. C. (2001). Effects of voluntary immigration on the distribution of autobiographical memory over the lifespan. Applied Cognitive Psychology. Special Issue: Trauma, stress, and autobiographical memory, 15(7), S75-S88. 
Schroots, J. J. F., van Dijkum, C., \& Assink, M. H. J. (2004). Autobiographical memory from a life span perspective. International Journal of Aging \& Human Development, 58(1), 69-85.

Sheehan, P. W. (1967a). A Shortened Form of Betts' Questionnaire Upon Mental Imagery. Journal of Clinical Psychology, 23(3), 386-389.

Sheehan, P. W. (1967b). Visual Imagery and the Organizational Properties of Perceived Stimuli. British Journal of Psychology, 58(3-4), 247252.

Sheehan, P. W. (1971). The role of imagery in incidental learning. British Journal of Psychology. Vol., 62(2), 235-243.

Stevenson, R. J., \& Case, T. I. (2004). Olfactory dreams: Phenomenology relationship to volitional imagery and odor identification. Imagination, Cognition and Personality, 24(1), 69-90.

Stevenson, R. J., \& Case, T. I. (2005). Olfactory imagery: A review. Psychonomic Bulletin \& Review, 12(2), 244-264.

Svoboda, E., McKinnon, M. C., \& Levine, B. (2006). The functional neuroanatomy of autobiographical memory: a meta-analysis. Neuropsychologia, 44(12), 2189-2208.

Thompson, C. P. (1982). Diary-keeping as a sex-role behavoir. Bulletin of the Psychonomic Society, 20, 11-13.

Thomsen, D. K., \& Berntsen, D. (2005). The end point effect in autobiographical memory: More than a calendar is needed. Memory, 13(8), 846-861.

Tulving, E. (1983). Elements of episodic memory. Oxford: Oxford University Press.

Tulving, E. (1998). Neurocognitive processes of human memory. In C. von Euler, I. Lundberg \& R. Llinas (Eds.), Basic mechanisms in cognition and language (pp. 261-281). Amsterdam: Elsevier.

Tulving, E. (2000). Concepts of memory. In E. Tulving \& F. I. M. Craik (Eds.), The Oxford handbood of memory (pp. 33-43). Oxford: Oxford University Press.

Tulving, E. (2002). Episodic memory: from mind to brain. Annu Rev Psychol, 53, 1-25.

Tulving, E., \& Thomson, D. M. (1973). Encoding specificity and retrieval processes in episodic memory. Psyhological Review, 80(5), 352-373.

Wagenaar, W. A. (1986). My memory: A study of autobiographical memory over six years. Cognitive Psychology, 18(2), 225-252.

Walker, W. R., Skowronski, J. J., Gibbons, J. A., Vogl, R. J., \& Thompson, C. P. (2003). On the emotions that accompany autobiographical memories: Dysphoria disrupts the fading affect bias. Cognition \& Emotion, 17(5), 703-723.

Walker, W. R., Vogl, R. J., \& Thompson, C. P. (1997). Autobiographical memory: Unpleasantness fades faster than pleasantness over time. Applied Cognitive Psychology, 11(5), 399-413.

Weisfeld, G. E., Czilli, T., Phillips, K. A., Gall, J. A., \& Lichtman, C. M. (2003). Possible olfaction-based mechanisms in human kin recogni- 
tion and inbreeding avoidance. Journal of Experimental Child Psychology, 85(3), 279-295.

Wheeler, M. A., Stuss, D. T., \& Tulving, E. (1997). Toward a theory of episodic memory: the frontal lobes and autonoetic consciousness. Psychological Bulletin, 121(3), 331-354.

Willander, J., \& Larsson, M. (2006). Smell your way back to childhood: Autobiographical odor memory. Psychonomic Bulletin \& Review, 13(2), 240-244.

Willander, J., \& Larsson, M. (2007a). Olfaction and emotion: The case of autobiographical memory. Memory \& Cognition, 35(7), 1659-1663.

Willander, J., \& Larsson, M. (2007b). The mind's nose and autobiographical odor memory. Submitted.

Zatorre, R. J. (2005). Mental concerts: musical imagery and auditory cortex. Neuron, 47(7), 9-12. 